\title{
Monetary Commitment and Fiscal Discretion: The Optimal Policy Mix
}

\author{
By Stefano Gnocchi*
}

\begin{abstract}
We study a noncooperative policy game between monetary and fiscal policy, where only monetary policy can commit to future actions. The equilibrium outcome of the game depends on the strategies available to the monetary policymaker. If strategies are left unrestricted, the central bank can alter the incentives of the fiscal authority in a way that replicates the full commitment solution. If the central bank cannot commit to respond to fiscal policy, the fiscal authority generates fluctuations in government expenditure that undermine the stabilization goals of the central bank. (JEL E12, E23, E31, E52, E58, E62)
\end{abstract}

$\mathrm{t}$ is natural to argue that monetary and fiscal policymakers do not share the same ability to credibly commit to future policies. In fact, monetary and fiscal policy decisions are taken in the context of remarkably different institutional environments. Central bank independence has contributed to assigning a prominent role to transparency and accountability about explicitly stated policy objectives that, in the case of inflation targeting central bankers, are defined by statute. In contrast, fiscal policy is conducted by political institutions, such as governments and parliaments, their tenure is limited in time, and their objectives are not as clearly established as the ones for monetary authorities since their mandate is defined by and evaluated according to electoral promises. At present, mechanisms designed to contain the credibility problems affecting sequential policy making are at best imperfect for fiscal policy. Hence, fiscal authorities bear a constraint that central bankers are less likely to face. Given such asymmetry, it is interesting to ask whether fiscal discretion undermines the objectives pursued by the monetary authority and how it affects the optimal monetary response.

In this paper, we investigate the interaction between monetary and fiscal policy under alternative commitment regimes. When both authorities have a similar ability to commit, either because both can commit or because neither cannot commit,

\footnotetext{
* Department of Economics and Economic History, Universitat Autònoma de Barcelona and Barcelona GSE; Campus UAB, Edifici B, 08193, Bellaterra, Barcelona, Spain (e-mail: stefano.gnocchi@uab.cat). I am indebted to Jordi Galí. I thank an anonymous referee for the insightful comments. I have benefited from conversations and suggestions by Alessia Campolmi, Chiara Forlati, Daniela Hauser, Luisa Lambertini, Albert Marcet, Jordi Massó, Evi Pappa, Elena Pastorino, Michael Reiter, Thijs van Rens, and Riccardo Rovelli. The financial support from the Spanish Ministry of Economy and Competitiveness through grant ECO2012-32392 and the Barcelona Graduate School Research Network is gratefully acknowledged.

${ }^{\dagger}$ To comment on this article in the online discussion forum, or to view additional materials including the author disclosure statement(s), visit the article page at http://dx.doi.org/10.1257/mac.5.2.187.
} 
monetary policy carries the full burden of stabilization, and fiscal policy is in some sense neutral. This is a known result discussed by Galí and Monacelli (2008) and Eser, Leith, and Wren-Lewis (2009). The novel contribution of this paper is to consider the case where the central bank never reneges on early promises and the fiscal policymaker cannot commit. The equilibrium outcome of the policy game depends on the strategies available to the central bank. If these strategies are unrestricted, the optimal stabilization plan achieved under commitment and coordination on the part of all policymakers (henceforth, full commitment for short) can be sustained, even though the fiscal authority cannot commit. In fact, the central bank chooses a strategy altering the incentives of the fiscal authority in such a way that it operates as if it could commit. A more interesting and, we will argue, more realistic case, is one in which the central bank cannot commit to respond to fiscal policy. In such a case, the fiscal authority has the incentive to generate higher volatility of government expenditure, as compared to the full commitment solution, and the central bank can dampen the fluctuations of public spending only by tolerating deviations of inflation and/or of the output gap from the full commitment plan.

Our findings contribute to the policy debate and to the literature along several dimensions. First, the policy debate about monetary and fiscal interaction has so far mostly centered around the inflationary consequences of debt monetization, since Sargent and Wallace (1981). We show that even in the absence of public debt, the achievement of the central bank's objectives may be compromised if the monetary authority can commit and the fiscal policymaker cannot. The argument follows directly from the seminal contribution by Kydland and Prescott (1977). Even though both authorities are benevolent and seek to maximize social welfare, they solve different problems. The central bank would like to smooth the impact of shocks over the cycle and transfer part of their burden to the future. In the event of a bad shock generating a short-run stabilization trade-off, committing to future deflation and recession allows to reduce current inflation at a lower cost in terms of output. This expectation channel improves current stabilization trade-offs. However, the fiscal policymaker chooses sequentially and overlooks the benefits of the current tightening in terms of past outcomes. Therefore, the use of government expenditure to stabilize business cycles, often regarded as complementary to monetary policy, is potentially detrimental rather than welfare improving. The final outcome ultimately depends on the way the monetary and fiscal authorities interact strategically.

Second, optimal monetary policy is commonly investigated either assuming away fiscal policy or under the assumption that a single authority chooses all the policy instruments. [n this paper we argue that when the two authorities do not share the same ability to commit, the way they interact needs to be explicitly modelled as it is crucial for the policy outcomes and their welfare implications. If one is willing to assume that the central bank perfectly observes the fiscal instruments, the optimal strategy prescribes to punish deviations of fiscal policy from the full commitment plan. For instance, the central bank raises the nominal interest rate if the

\footnotetext{
${ }^{1}$ As a representative sample, see Rotemberg and Woodford (1997); Clarida, Galí, and Gertler (1999); Galí (2003); Galí and Monacelli (2008); Beetsma and Jensen (2005); Schmitt-Grohé and Uribe (2007, 2004); and Leith and Von Thadden (2008).
} 
fiscal policymaker overexpands government expenditure, so as to let her internalize the cost of the deviation through a fall of the output gap. As there exists a credible punishment that is tough enough to make any fiscal deviation unprofitable, full commitment is sustained and the threat is never executed at equilibrium. However, reliable data on government expenditures are released with nontrivial lags, so that one may be willing to assume that public spending is observed with some noise. In such a case, discouraging fiscal misbehavior by manipulating the nominal interest rate becomes costly. In fact, in order to be credible, the central bank needs to punish every deviation, even if it is due to some measurement error. Under noisy information, it is optimal to combine two kinds of reaction to fiscal misbehavior. On the one hand, the nominal interest rate reacts to fluctuations of government expenditure, but not necessarily as much as predicted by the optimal strategy with perfect information. On the other hand, the central bank tolerates deviations of inflation and/or of the output gap from the full commitment plan. This is a way to manipulate the fiscal authority's stabilization trade-off and give her the incentive to dampen fluctuations of government expenditure. When the information available to the central bank is sufficiently noisy, the monetary authority simply commits to an interest rate path that is not contingent on fiscal policy choices. Therefore, a situation where the central bank does not respond to fiscal policy is the optimal limiting behavior when the noise grows large.

Finally, our analysis has some implications for the evaluation of gains from monetary commitment, emphasized by Rotemberg and Woodford (1997), Clarida, Galí, and Gertler (1999), and Galí (2003), even in the absence of an inflation bias due to steady-state distortions. If the nominal interest rate fails to respond to fiscal misbehavior, gains from monetary commitment are considerably reduced. In particular, under our baseline parametrization, the welfare gain is half of the one that would be observed under commitment from all policymakers.

At present, the literature on policy games between monetary and fiscal policy is still rather scant. Our contribution is closely related to Adam and Billi (2008) and Dixit and Lambertini (2003). The former consider the case of independent monetary and fiscal policymakers both acting under discretion and discuss the desirability of installing a conservative central banker, as suggested by Rogoff (1985), in order to eliminate the steady-state biases associated with discretion. Adam and Billi (2008) also compute the steady-state of a deterministic model with steady-state distortions, where the central bank acts under commitment and fiscal policy acts under discretion. However, they restrict to a steady-state analysis. As a consequence, they do not discuss the implications of government expenditure volatility for the optimal monetary policy rule and they do not address the stabilization bias issue, as we do here along the lines of Galí (2008) or Woodford (2003). Dixit and Lambertini (2003), the first authors who take explicitly into account the lack of coordination between the two authorities in a game theoretic fashion, also depart from benevolent policymakers. In addition, they address the issue in the context of a static model. Hence, they are silent about the monetary policy problem we investigate here.

The paper is organized as follows. Section I describes the model economy and the competitive equilibrium. Section II analyzes the benchmark of monetary and fiscal policy coordination. Section III describes the policy game and finds the optimal monetary and fiscal policy strategies. Section IV concludes. 


\section{The Private Sector Equilibrium}

We consider a standard New-Keynesian model as in Galí (2008) or Woodford (2003). A closed production economy is populated by infinitely many households and firms interacting on goods, labor, and asset markets. In the economy there is a perfectly competitive final good sector that produces and sells a homogeneous final good to households and to the fiscal policymaker. The final good sector uses as input a continuum of imperfectly substitutable intermediate goods, each of them produced by a monopolistically competitive firm hiring labor services supplied by households. The prices of intermediate goods are set in staggered contracts with random duration. Labor markets are monopolistically competitive and the wage markup is assumed to fluctuate exogenously around its mean value to create a meaningful policy trade-off between output and inflation stabilization. Financial markets are complete.

There are two policymakers: a monetary authority that sets the nominal interest rate and a fiscal authority that is responsible for choosing the level of government expenditure. We assume that the fiscal authority has access to three tax instruments: a production subsidy, a labor income subsidy, and a lump sum tax that is used to finance expenditure. We also assume that the production and labor income subsidies cannot be adjusted in a state-contingent way. Therefore, they solely serve the purpose of eliminating steady-state distortions due to monopolistic competition and cannot be used for stabilization policy, whereas the lump-sum tax can. Given that consumers are Ricardian, the timing of the lump-sum tax does not matter, hence, we assume for concreteness that the fiscal authority balances its budget in every period. ${ }^{2}$

\section{A. Inflation and Output Dynamics}

We directly report the model in its log-linear version. ${ }^{3}$ The steady-state of the solution to the policy problem coincides with the steady-state of the Pareto efficient allocation under all the policy regimes we consider. ${ }^{4}$ In fact, the fiscal authority is allowed to appropriately subsidize labor income and production financing subsidies with lump-sum taxation. Let output, government expenditure, and fiscal gaps be respectively defined as

$$
y_{t}=\hat{y}_{t}-\bar{y}_{t} ; \quad g_{t}=\hat{g}_{t}-\bar{g}_{t} ; \quad f_{t}=g_{t}-y_{t} .
$$

Lower case variables with a hat denote log deviations from the steady-state and lower case variables with a bar denote log deviations of the Pareto efficient equilibrium. $f_{t}$ is the percentage deviation from efficiency of government expenditure as a

\footnotetext{
${ }^{2}$ The paper is not about the fiscal theory of the price level or the interaction between public deficits and monetary policy.

${ }^{3}$ Appendix A provides a detailed description of the model, the Pareto efficient allocation, and the log-linearization of the first-order conditions about the nonstochastic steady-state.

${ }^{4}$ The claim is proved in Appendix C, available upon request.
} 
fraction of output. One can show that inflation and the output gap are fully described by

$$
\begin{gathered}
\pi_{t}=\beta E_{t}\left\{\pi_{t+1}\right\}+\lambda(1+\varphi) y_{t}-\lambda \frac{\chi}{1-\chi} f_{t}+\lambda \mu_{t}^{w} \\
y_{t}=E_{t}\left\{y_{t+1}\right\}+\frac{\chi}{1-\chi} f_{t}-\frac{\chi}{1-\chi} E_{t}\left\{f_{t+1}\right\}-\left(r_{t}-E_{t}\left\{\pi_{t+1}\right\}-r r_{t}\right) .
\end{gathered}
$$

Parameters can be conventionally interpreted as follows. $\beta$ is the discount factor; $\lambda$ is a convolution of parameters defined in Appendix A and is a decreasing function of price stickiness; $\varphi$ is the inverse of the Frisch elasticity of labor supply; $\chi$ parameterizes the steady-state share of public spending; while $r r_{t}$ is only a function of technology shocks as shown in Appendix A. Equation (2) is a conventional Phillips curve, with an additional term $-\lambda \chi(1-\chi)^{-1} f_{t}$ capturing the impact of government expenditure on inflation. Given output, a rise in $f_{t}$ crowds out private consumption and reduces the real wage and the real marginal cost by increasing households' willingness to work. The presence of a cost-push shock, $\mu_{t}^{w}$, makes it impossible to simultaneously stabilize inflation, the output and the fiscal gaps. Equation (3) directly follows from the consumption Euler equation and it is a conventional IS curve. The fiscal gap appears since consumption has been replaced by using the resource constraint.

\section{B. Competitive Equilibrium}

We define the notion of competitive equilibrium as in Barro (1979) and Lucas and Stokey (1983), where decisions of the private sector as well as policies can be described by a collection of rules mapping the history of exogenous events into decisions. Let $\mathbf{s}^{t}=\left(\mathbf{s}_{0}, \ldots, \mathbf{s}_{t}\right)$ be the history of exogenous events, where $\mathbf{s}_{t}=\left(r r_{t}, \mu_{t}^{w}\right)$. Define

$$
\begin{aligned}
& \mathcal{C}_{0} \equiv\left\{f_{t}\left(\mathbf{s}^{t}\right), r_{t}\left(\mathbf{s}^{t}\right), \pi_{t}\left(\mathbf{s}^{t}\right), y_{t}\left(\mathbf{s}^{t}\right)\right\}_{t \geq 0} \\
& \mathcal{C}_{t} \equiv\left\{f_{r}\left(\mathbf{s}^{r} \mid \mathbf{s}^{t}\right), r_{r}\left(\mathbf{s}^{r} \mid \mathbf{s}^{t}\right), \pi_{r}\left(\mathbf{s}^{r} \mid \mathbf{s}^{t}\right), y_{r}\left(\mathbf{s}^{r} \mid \mathbf{s}^{t}\right)\right\}_{r \geq t} .
\end{aligned}
$$

Hence, $\mathrm{C}_{0}$ is a competitive equilibrium if it satisfies equations (2) and (3) for any $s^{t}$. $\bigodot_{t}$ is a continuation competitive equilibrium starting at history $\mathbf{s}^{t}$ if it satisfies equations (2) and (3) for any $\mathbf{s}^{r}$ with $r \geq t$ and $t \geq 0$. Obviously, a continuation competitive equilibrium starting at $\mathbf{s}^{0}$ is simply a competitive equilibrium.

\section{Coordinated Optimal Policies}

We first characterize as a benchmark the case of coordination, where a single authority chooses both monetary and fiscal policy, either under commitment or 
under discretion. A second-order approximation to the utility function about the nonstochastic steady-state yields the following welfare function:

$$
W_{t}=-\frac{1}{2} E_{t} \sum_{j=0}^{\infty} \beta^{j}\left(\frac{\epsilon_{p}}{\lambda} \pi_{t+j}^{2}+(1+\varphi) y_{t+j}^{2}+\frac{\chi}{1-\chi} f_{t+j}^{2}\right)
$$

which is assumed to be the objective of the policymaker. The parameter $\epsilon_{p}$ denotes the elasticity of substitution across intermediate goods. The optimal plan under commitment is a competitive equilibrium maximizing $W_{0}$. Optimality requires

$$
\begin{gathered}
\epsilon_{p} \pi_{t}+\Delta y_{t}=0 \\
f_{t}+y_{t}=g_{t}=0,
\end{gathered}
$$

where (5) and (6) are the monetary and the fiscal targeting rules, respectively. 5 Then, the optimal policy mix under commitment implies that $g_{t}=0$, a case that deserves some attention.

DEFINITION 1: If $g_{t}=0$, the fiscal stance is said to be neutral.

Such a situation can be interpreted as if the policymaker focused on public goods provision and monetary policy carried the full burden of stabilization. Throughout the paper, we refer to the policy defined by (5)-(6) as the full commitment solution.

The optimal plan under discretion is a competitive equilibrium $\mathcal{C}_{0}$ such that any of its continuations $\bigodot_{t}$ maximize $W_{t}$, given the continuation $\bigodot_{t+1}$. As opposed to commitment, under discretion optimality is defined sequentially and it requires

$$
\epsilon_{p} \pi_{t}+y_{t}=0
$$

while equation (6) still holds. By comparing commitment and discretion, a first result emerges.

RESULT 1: If monetary and fiscal policy share the same ability to commit, either because both can commit or because neither can, the optimal fiscal policy stance is neutral.

Hence, we can conclude that symmetry in the policy regime implies full stabilization of the government expenditure gap, irrespective of whether policy is conducted by committed or discretionary policymakers. Throughout the paper we refer to the policy defined by (6) and (7) as the full discretion solution.

\footnotetext{
${ }^{5}$ Equation (5) is the conventional targeting rule extensively discussed in the literature. See Galí (2008) or Woodford (2003).
} 


\section{Monetary Commitment and Fiscal Discretion}

We now turn to the case where monetary and fiscal policies are conducted by two independent authorities. Only the former is able to credibly commit to future policies, while fiscal policy is conducted in a discretionary fashion. Hence, at time $t=0$, monetary policy commits to an interest rate rule maximizing her objective, and she sticks to the plan for all $t \geq 0$. In contrast, fiscal policy chooses the fiscal gap at each point in time.

In this section we proceed as follows. First, we give a formal description of the policy game, specifying the strategy space and the equilibrium concept. We follow the same formalism as Chari and Kehoe (1990) and Atkeson, Chari, and Kehoe (2010), i.e., we allow allocations, prices, and policies to be functions of the history of both the aggregate private actions and policies, as well as the history of exogenous events. Second, we compute the equilibrium fiscal and monetary strategies. Finally, we characterize the allocation in the optimal policy mix.

\section{A. The Policy Game}

We want to focus on the interaction between the policymakers and we regard private agents as a constraint defining the set of implementable allocations. Hence, we do not view households and price setters as strategically interesting. ${ }^{6}$ Consequently, there are only two players: the central bank and the fiscal authority.

Timing.-At time $t=0$, at a stage that may be viewed as constitutional, the central bank chooses an interest rate rule, say $\boldsymbol{\sigma}_{r}$, contingent on all the information available, when $r_{t}$ will have to be set. The rule, once in place, cannot be changed at later stages. Below we specify and discuss in detail the information available to each player, the class of monetary policy rules we restrict to, as well as the fiscal strategy space. Here, we first define the order of moves. After the constitutional stage, for all $t \geq 0$, events unfold in the following order:

- Shocks occur. They are observed by the players and by the private sector.

- The fiscal policymaker chooses $f_{t}$.

- The central bank keeps her promise by setting the nominal interest rate $r_{t}$ according to rule $\boldsymbol{\sigma}_{r}$.

- Inflation and the output gap realize.

The events occurring in any period $t$ can be represented in chronological order by $\mathbf{q}_{t}=\left(\mathbf{s}_{t}, f_{t}, r_{t},\left(\pi_{t}, y_{t}\right)\right)$. Denoting the history of the game as $\mathbf{h}_{t}$, it follows that $\mathbf{h}_{t}=\left(\mathbf{h}_{t-1}, \mathbf{q}_{t}\right)$ for $t \geq 1$ and $\mathbf{h}_{0}=\mathbf{q}_{0}$. Timing makes clear the leadership structure

\footnotetext{
${ }^{6}$ In contrast, Atkeson, Chari, and Kehoe (2010) study off-equilibrium behavior of price setters so as to find monetary policy strategies uniquely implementing any competitive equilibrium. In order to do so, they construct policies discouraging firms' deviations from the unique bounded solution associated with interest rate rules satisfying the Taylor principle. To simplify the game, we abstract from this interaction. Simplicity comes at the price of ensuring uniqueness of the equilibrium only locally, as it is conventionally done in the monetary literature relying on Taylor rules.
} 
of the game. Because of commitment, the monetary authority does not make any relevant choice after the constitutional stage, instead she simply executes plan $\sigma_{r}$. Then, the monetary policymaker is the leader of both the private sector and the fiscal authority, while the latter only leads households and firms.]

Histories and Strategies.-The fiscal policymaker, facing histories $\mathbf{h}_{t F}=\left(\mathbf{h}_{t-1}, \mathbf{s}_{t}\right)$, chooses her instrument in each period after observing the realization of the shocks, in addition to the whole history of the game. $\mathbf{h}_{t M}=\left(\mathbf{h}_{t-1}, \mathbf{s}_{t}, f_{t}\right)$ denotes the information available to the central bank, who executes her plan after observing the fiscal gap. Finally, inflation and the output gap are contingent on $\mathbf{h}_{t Y}=\left(\mathbf{h}_{t-1}, \mathbf{s}_{t}, f_{t}, r_{t}\right)$. Consequently, strategies are sequences $\boldsymbol{\sigma}_{r}=\left\{r_{t}\left(\mathbf{h}_{t M}\right)\right\}_{t \geq 0}$ and $\boldsymbol{\sigma}_{f}=\left\{f_{t}\left(\mathbf{h}_{t F}\right)\right\}_{t \geq 0}$ mapping histories into the policy instruments, while private decisions are represented by some allocation rules $\boldsymbol{\sigma}_{\pi}=\left\{\pi_{t}\left(\mathbf{h}_{t Y}\right)\right\}_{t \geq 0}$ and $\boldsymbol{\sigma}_{y}=\left\{y_{t}\left(\mathbf{h}_{t Y}\right)\right\}_{t \geq 0}$. For any sequence of exogenous events from period 0 onward, $\boldsymbol{\sigma}=\left(\boldsymbol{\sigma}_{f}, \boldsymbol{\sigma}_{r}, \boldsymbol{\sigma}_{\pi}, \boldsymbol{\sigma}_{y}\right)$ naturally induces outcomes as well as continuation outcomes starting from any given history $\mathbf{h}_{t-1}$. We show a recursion for a generic period $t$. After $\mathbf{s}_{t}$ is realized and observed by the fiscal authority, $f_{t}\left(\mathbf{s}^{t} \mid \mathbf{h}_{t-1} ; \boldsymbol{\sigma}\right)$ $=f_{t}\left(\mathbf{h}_{t F}\right), f_{t}$ being obtained from $\boldsymbol{\sigma}_{f}$. Then, $\mathbf{h}_{t M}=\left(\mathbf{h}_{t-1}, \mathbf{s}_{t}, f_{t}\left(\mathbf{s}^{t} \mid \mathbf{h}_{t-1} ; \boldsymbol{\sigma}\right)\right)$ and $r_{t}\left(\mathbf{s}^{t} \mid \mathbf{h}_{t-1} ; \boldsymbol{\sigma}\right)=r_{t}\left(\mathbf{h}_{t M}\right)$, where $r_{t}$ follows from $\boldsymbol{\sigma}_{r}$. Finally, by using $\boldsymbol{\sigma}_{\pi}$ and $\boldsymbol{\sigma}_{y}$, the information set $\mathbf{h}_{t Y}=\left(\mathbf{h}_{t-1}, \mathbf{s}_{t}, f_{t}\left(\mathbf{s}^{t} \mid \mathbf{h}_{t-1} ; \boldsymbol{\sigma}\right), r_{t}\left(\mathbf{s}^{t} \mid \mathbf{h}_{t-1} ; \boldsymbol{\sigma}\right)\right)$ allows to determine inflation and output. Similarly, outcomes can be generated for all future possible exogenous events $\mathbf{s}^{r}$ with $r \geq t$ and $t \geq 0$, conditionally on the information $\mathbf{h}_{t-1}$. Hence, we can define continuation outcomes of the game as

$$
\mathcal{A}\left(\mathbf{h}_{t-1} ; \boldsymbol{\sigma}\right) \equiv\left\{f_{t}\left(\mathbf{s}^{r} \mid \mathbf{h}_{t-1} ; \boldsymbol{\sigma}\right), r_{t}\left(\mathbf{s}^{r} \mid \mathbf{h}_{t-1} ; \boldsymbol{\sigma}\right), \pi_{t}\left(\mathbf{s}^{r} \mid \mathbf{h}_{t-1} ; \boldsymbol{\sigma}\right), y_{t}\left(\mathbf{s}^{r} \mid \mathbf{h}_{t-1} ; \boldsymbol{\sigma}\right)\right\}_{r \geq t} .
$$

Obviously, $\mathcal{A}(\boldsymbol{\sigma})$ is simply the outcome of the game from period 0 onward. Also, we can generate continuation outcomes from any of the histories $\mathbf{h}_{t F}, \mathbf{h}_{t M}$, and $\mathbf{h}_{t Y}$ in the same way. For instance, we denote by $\mathcal{A}\left(\mathbf{h}_{t y} ; \boldsymbol{\sigma}\right)$ the continuation from $\mathbf{h}_{t y}$. Similarly, we define continuation strategies at any history. For example, $\boldsymbol{\sigma}_{f}^{t+1}=\left\{f_{r}\left(\mathbf{s}^{r} \mid \mathbf{h}_{t F}\right)\right\}_{r \geq t+1}$ denotes the continuation of the fiscal strategy from $\mathbf{h}_{t F}$ onward. The objective function $W_{t}$ ranks continuation outcomes starting from any history. Since the central bank commits to $\sigma_{r}$ at the constitutional stage, she evaluates alternative outcomes according to $W_{0}$, as opposed to the fiscal policymaker that, acting sequentially, maximizes $W_{t}$ for any possible history $\mathbf{h}_{t-1}$.

Equilibrium of the Policy Game.-We are finally ready to define the equilibrium along the same lines as Atkeson, Chari, and Kehoe (2010).

DEFINITION 2: An equilibrium of the policy game is a collection of strategies and allocation rules $\boldsymbol{\sigma}^{*}$ such that: ( $i$ ) for any $\mathbf{h}_{t Y}, \boldsymbol{\sigma}_{\pi}^{*}$, and $\boldsymbol{\sigma}_{y}^{*}$ induce continuation

\footnotetext{
${ }^{7}$ Inverting the order of moves within each time period after the constitutional stage would only imply a loss of tractability, but it would not change our results. In fact, the central bank could still condition the nominal interest rate on $f_{t-1}$. Different is the case of sequential policy making, as in Adam and Billi (2008), where the timing also determines the leadership structure, because of lack of commitment on both the monetary and the fiscal side.
} 
outcomes $\mathcal{A}\left(\mathbf{h}_{t Y} ; \boldsymbol{\sigma}\right)$ that are continuation competitive equilibria; (ii) for any $\boldsymbol{\sigma}_{r}$, $\boldsymbol{\sigma}_{f}^{*}$ maximizes ${ }_{t}^{W}$ at any history $\mathbf{h}_{t F}$, given the continuation $\boldsymbol{\sigma}_{f}^{* t+1}$; (iii) given $\boldsymbol{\sigma}_{f}^{*}, \boldsymbol{\sigma}_{r}^{*}$ maximizes $W_{0} \cdot 8$

The equilibrium notion invokes perfection. ${ }^{9}$ In fact, a Nash equilibrium would only require optimality of $\boldsymbol{\sigma}_{f}^{*}$ at the equilibrium strategy $\boldsymbol{\sigma}_{r}^{*}$, leaving unrestricted fiscal behavior off-equilibrium and opening the possibility of noncredible threats.

Monetary and Fiscal Strategies.-The following proposition ${ }^{10}$ shows that one can restrict the search of equilibrium strategies to a particular class of policy rules. In fact, within that class, for any competitive equilibrium there exists a pair of strategies $\sigma_{r}$ and $\sigma_{f}$ that can support it.

PROPOSITION 1: Let $\mathrm{C}_{0}$ be a bounded competitive equilibrium and be $\left(\hat{\boldsymbol{\sigma}}_{\pi}, \hat{\boldsymbol{\sigma}}_{y}\right)$ such that for any $\boldsymbol{\sigma}_{r}$ and $\boldsymbol{\sigma}_{f}, \mathcal{A}\left(\mathbf{h}_{t Y} ; \boldsymbol{\sigma}\right)$ is a continuation competitive equilibrium. Let $r_{t}^{*}\left(\mathbf{s}^{t}\right), \pi_{t}^{*}\left(\mathbf{s}^{t}\right)$ and $f_{t}^{*}\left(\mathbf{s}^{t}\right)$ belong to $\mathrm{C}_{0}$. For any $\gamma_{f}$ and any $\gamma_{\pi}>1$, define monetary and fiscal strategies $\hat{\sigma}_{r}$ and $\hat{\sigma}_{f}$ :

$$
\begin{gathered}
r_{t}\left(\mathbf{h}_{t M}\right)=r_{t}^{*}\left(\mathbf{s}^{t}\right)+\gamma_{f}\left(f_{t}\left(\mathbf{h}_{t F}\right)-f_{t}^{*}\left(\mathbf{s}^{t}\right)\right)+\gamma_{\pi}\left(\pi_{t}\left(\mathbf{h}_{t Y}\right)-\pi_{t}^{*}\left(\mathbf{s}^{t}\right)\right) \\
f_{t}\left(\mathbf{h}_{t F}\right)=F_{t}\left(\mathbf{s}^{t}\right),
\end{gathered}
$$

where $F_{t}$ is linear. Then, if $F_{t}=f_{t}^{*}$ for any $\mathbf{s}^{t}$, there exists a unique bounded outcome $\mathcal{A}_{0}(\hat{\boldsymbol{\sigma}})$ coinciding with $\mathrm{C}_{0}$.

The monetary strategy (8) is a Taylor-type rule and is a function of inflation. Solving for the interest rate requires finding a fixed point. In fact, $r_{t}\left(\mathbf{h}_{t M}\right)$ also appears on the right-hand side of the equation, because $\pi_{t}\left(\mathbf{h}_{t Y}\right)$ can be recovered from $\boldsymbol{\sigma}_{\pi}^{*}$ only by knowing $r_{t}\left(\mathbf{s}^{t} \mid \mathbf{h}_{t-1} ; \hat{\boldsymbol{\sigma}}\right)$. Since the strategy of the fiscal authority is solely a function of $\mathbf{s}^{t}$, the problem greatly simplifies: solving the system of linear difference equations formed by (2), (3), and (8) does not require to keep track of any additional state other than $\mathbf{s}^{t}$. Hence, the equilibrium nominal interest rate, inflation and the output gap can be, respectively, written as $r_{t}\left(\mathbf{s}^{t} ; \hat{\boldsymbol{\sigma}}\right), \pi_{t}\left(\mathbf{s}^{t} ; \hat{\boldsymbol{\sigma}}\right)$, and $y_{t}\left(\mathbf{s}^{t} ; \hat{\boldsymbol{\sigma}}\right)$. Given the simplicity of $\hat{\boldsymbol{\sigma}}_{r}$ and $\hat{\boldsymbol{\sigma}}_{f}$, we look for equilibrium strategies in the classes defined by (8) and (9). Our assumptions are not particularly restrictive. In fact, could monetary and fiscal strategies be chosen jointly, any competitive equilibrium is attainable, including the full commitment solution, which is constrained efficient. In addition, we show below that there exists a rule (8) that still implements the full commitment allocation at the equilibrium of the policy game, even though the fiscal authority acts in a discretionary fashion. More restrictive is the form of the fiscal strategy,

\footnotetext{
${ }^{8}$ If conditions for a continuation competitive equilibrium hold at any $\mathbf{h}_{t Y}$, then they also hold at $\mathbf{h}_{t F}$ and $\mathbf{h}_{t M}$. In other words, we require (2) and (3) to be satisfied for any history.

${ }^{9}$ As Chari and Kehoe (1990) have already emphasized, the distinction between commitment and time-consistent equilibrium is not perfection that is required in both cases; they simply correspond to perfect equilibria of two different games.

${ }^{10}$ See Appendix B for the proof.
} 
which is assumed to depend on the history of exogenous events only. However, the assumption is standard when modelling discretion, since it excludes a multiplicity of reputational equilibria. ${ }^{11}$

According to Definition 2, under our strategy restrictions the central bank affects the policy trade-offs faced by the fiscal authority. It follows that the optimal fiscal strategy is a linear function of $\mathbf{s}^{t}$ that, at equilibrium, must depend on the monetary rule. By backward induction, the central bank correctly anticipates fiscal behavior that in turn affects the optimal strategy $\boldsymbol{\sigma}_{r}^{*}$. A simple example can illustrate how the monetary and fiscal authorities interact. Consider $\sigma_{r}$ and $\sigma_{f}$, such that (i) $r_{t}^{*}\left(\mathbf{s}^{t}\right)$, $\pi_{t}^{*}\left(\mathbf{s}^{t}\right)$ and $f_{t}^{*}\left(\mathbf{s}^{t}\right)$ satisfy the full commitment solution; (ii) in contrast, $F_{t}\left(\mathbf{s}^{t}\right)$ $=f_{t}^{*}\left(\mathbf{s}^{t}\right)$ for all $t \neq j$, while $F_{j}\left(\mathbf{s}^{j}\right)$ deviates from $f_{j}^{*}\left(\mathbf{s}^{j}\right)$. Continuation outcomes from $\mathbf{h}_{j F}$ onward can be easily computed: for all $t>j$ the full commitment plan is enforced, while it can be shown after some algebra ${ }^{12}$ that in $t=j$

$$
r_{f} \equiv \frac{\partial r_{j}}{\partial f_{j}}=\Omega\left[\frac{\chi}{1-\chi} \gamma_{\pi} \lambda \varphi+\gamma_{f}\right] ; \quad \Omega \equiv \frac{1}{1+\gamma_{\pi} \lambda(1+\varphi)} .
$$

The response of the nominal interest rate feeds into inflation and the output gap through the conditions for a competitive equilibrium defining $\pi_{j}\left(\mathbf{s}_{j}, f_{j} \mid \mathbf{s}^{j-1} ; \boldsymbol{\sigma}\right)$ and $y_{j}\left(\mathbf{s}_{j}, f_{j} \mid \mathbf{s}^{j-1} ; \sigma\right)$. Therefore, if the fiscal authority sticks to the full commitment solution, so do inflation, the output gap, and the nominal interest rate. Otherwise, variables deviate by an amount that depends on $r_{f}$ and $f_{t}$ : continuation outcomes from $\mathbf{h}_{t F}$ are functions of parameters entering the monetary rule, in particular $r_{t}^{*}\left(\mathbf{s}^{t}\right)$, $\pi_{t}^{*}\left(\mathbf{s}^{t}\right), f_{t}^{*}\left(\mathbf{s}^{t}\right)$, and $r_{f}$.

In the next sections, we consider two sets of monetary strategies. We start by computing the optimal monetary policy rule within the family defined by (8). We refer to these rules as unrestricted monetary strategies. Then, we look for the optimal rule of the form (8) under the additional restriction that $r_{f}=0$. We refer to these rules as restricted monetary strategies, ${ }^{13}$ denoted by $\overline{\boldsymbol{\sigma}}_{r}$. Clearly, unrestricted strategies dominate restricted ones in terms of welfare. However, as we will argue extensively in Section IIIC, the restricted strategy characterizes the optimal limiting behavior in an environment where the central bank observes government expenditure with some noise and when the noise grows large..$^{14}$

\footnotetext{
${ }^{11}$ See for instance Klein, Krussell, and Ríos-Rull (2008). Instead, Chari and Kehoe (1990) provide an extensive discussion about the use of trigger type equilibria in infinite horizon games.

${ }^{12}$ Equations (2), (3), and (8) can be solved by taking as given expectations about future variables that in fact correspond for all $t>j$ to the commitment outcome, irrespective of the fiscal gap in $t=j$.

${ }_{13}$ Many contributions have analyzed dynamic policy games to tackle the issue of international cooperation. Similarly to our restricted strategy case, it is commonly assumed that the domestic central bank takes the instrument of the foreign policymaker as given. For a discussion, see Benigno (2002); Benigno and Benigno (2006); Canzoneri and Gray (1985); Canzoneri and Henderson (1992); Clarida, Galí, and Gertler (2002); Coenen et al. (2010); and Liu and Pappa (2008).

${ }^{14}$ The case $\gamma_{f}=0$ does not yield similar results. In fact, differently from the case $r_{f}=0$, the equilibrium outcomes depend on $\gamma_{\pi}$ and if that coefficient tends to infinity, full commitment can be implemented. However, such a policy is hardly desirable, because it does not provide the correct limiting behavior if the central bank can only observe the fiscal gap with some measurement error. In fact, when the inflation coefficient tends to infinity, $r_{f}$ is strictly positive, while we show in Section IIID that it has to be zero if the standard deviation of the measurement error grows large.
} 
Sections IIIB and IIIC present the equilibrium under unrestricted and restricted monetary strategies, respectively. In Section IIID, we discuss the relevance of both equilibria. Section IIIE concludes with the welfare implications of our analysis.

\section{B. Equilibrium under Unrestricted Strategies}

Given the leadership structure of the game, we first determine the optimal fiscal policy for any given monetary policy rule within the class (8). Then, we optimize over monetary rules.

Fiscal policy chooses $f_{t}$ so as to maximize $W_{t}$, subject to (2), (3), and (8), given the exogenous stochastic processes and expectations about future variables. Equations (2) and (3) are internalized, because the fiscal authority leads the private sector, while taking into account (8) guarantees sub-game perfection. Optimal fiscal policy under discretion implies the following targeting rule: $:^{15}$

$$
f_{t}+y_{t}=\delta_{r}\left(y_{t}+\epsilon_{p} \pi_{t}\right) ; \quad \delta_{r} \equiv \frac{(1+\varphi)(1-\chi)}{\chi} r_{f}-\varphi
$$

As comparing (11) to (7) makes it clear, if fluctuations of the government expenditure gap ${ }^{16}$ arise, it must be the case that the monetary strategy implies a deviation from the discretionary targeting rule (7). It is possible to show that the right-hand side of the targeting rule is proportional to the Lagrange multiplier, $\psi_{r, t}$, attached to the IS equation in the fiscal policy problem. $\psi_{r, t}$ can be interpreted as the marginal benefit of an exogenous fall in the nominal interest rate evaluated according to the fiscal authority's objective. Equivalently, it is the cost of the monetary stabilization plan perceived by the fiscal policymaker. Equation (11) simply states that if the central bank deviates from the discretionary targeting rule, the fiscal authority perceives the monetary plan as suboptimal. In particular, if the monetary stance is too tight, fiscal policy overexpands, as compared to a neutral fiscal stance. It follows that fluctuations of the government expenditure gap, if observed at equilibrium, are due to the asymmetry of the policy regime. Hence, we can state:

RESULT 2: If $\delta_{r}$ is different from zero, the optimal fiscal stance is neutral if and only if the discretionary monetary targeting rule (7) holds on the equilibrium path.

To establish whether the optimal policy mix involves deviations from a neutral fiscal stance, it is necessary to solve for the optimal monetary policy problem. We do it in two steps. First, for a given value of $\gamma_{f}$, we compute the competitive equilibrium

\footnotetext{
${ }^{15}$ The rule (11) implicitly defines the optimal fiscal strategy. In fact, one can find the optimal fiscal strategy after using the monetary strategy (8) into (2), (3), and (11) and by solving the system. It is evident from (11) that optimal fiscal policy must only depend on $r_{f}$, but not on $\gamma_{\pi}$ and $\gamma_{f}$ separately. Once $\gamma_{\pi}$ is chosen to ensure local uniqueness, an equilibrium can be equivalently supported by selecting either $\gamma_{f}$ or $r_{f}$.

${ }^{16}$ Recall that the government expenditure gap, $g_{t}=f_{t}+y_{t}$, is the $\log$ deviation of public spending from its Pareto efficient level.
} 
maximizing $W_{0}$, subject to the fiscal targeting rule (11) ${ }^{17}$. Then, we find the optimal $\gamma_{f}$. Conditionally on any $\gamma_{f}$, the targeting rule of the central bank reads as ${ }^{18}$

$$
\begin{aligned}
\epsilon_{p} \pi_{t} & +\frac{(1-\chi)(1+\varphi)}{(1-\chi)(1+\varphi)+\chi \delta_{y}} \Delta y_{t}-\frac{\chi \delta_{y}}{(1-\chi)(1+\varphi)+\chi \delta_{y}} \Delta f_{t} \\
& -\delta_{\pi} \frac{\chi \lambda(1+\varphi)}{(1-\chi)(1+\varphi)+\chi \delta_{y}}\left(f_{t}+y_{t}\right)=0 .
\end{aligned}
$$

One can show that by choosing

$$
\gamma_{f}=\gamma_{f}^{*} \equiv \frac{\chi}{1-\chi}\left[\frac{\varphi}{1+\varphi}\right] .
$$

$\delta_{r}=0$ for any $\gamma_{\pi}$. As a consequence, Result 2 does not apply and the fiscal stance remains neutral, while equations (11) and (12) reduce to the first-order conditions characterizing full commitment. Hence, let $\mathcal{C}_{0}^{C}$ be the competitive equilibrium associated to the full commitment solution. Therefore, by Proposition 1, the optimal monetary policy strategy is a rule of the form (8) with $\gamma_{f}=\gamma_{f}^{*}$, and functions $r_{t}^{*}\left(\mathbf{s}^{t}\right), \pi_{t}^{*}\left(\mathbf{s}^{t}\right), f_{t}^{*}\left(\mathbf{s}^{t}\right)$ belonging to $\mathcal{C}_{0}^{C}$. The monetary rule and the optimal fiscal strategy $F^{*}\left(\mathbf{s}^{t}\right)$ implied by condition (11) define the equilibrium of the policy game. We can then state the following result:

RESULT 3: In the optimal policy mix under unrestricted monetary strategies, the equilibrium outcome of the game coincides with the competitive equilibrium associated with the full commitment solution. Hence, the fiscal stance is neutral.

Intuitively, the central bank threatens the fiscal authority with raising the nominal interest rate, if government expenditure is higher than the level prescribed by a neutral fiscal stance. Such a reaction on the part of the monetary authority is costly for the fiscal policymaker, because it lowers the marginal gain of a fiscal expansion in terms of the output gap. Should a deviation occur, the benefit of the deviation would be exactly offset by the monetary tightening. Hence, the fiscal stance remains neutral on the equilibrium path.

\section{Equilibrium under Restricted Strategies}

Under restricted strategies, the central bank commits to (8) after imposing the additional restriction $r_{f}=0$, which, by equation (10), is equivalent to setting

$$
\gamma_{f}=\gamma_{f}^{* *} \equiv-\frac{\chi}{1-\chi} \gamma_{\pi} \lambda \varphi
$$

\footnotetext{
${ }^{17}$ In Appendix B we prove that it is immaterial whether the central bank internalizes the targeting rule (11) or the optimal fiscal strategy $F^{*}$ of the form (9).

${ }^{18}$ See equation (B12) in Appendix B for a definition of the coefficients.
} 
Under restricted strategies, the monetary rule does prescribe the same nominal interest rate path, irrespective of whether the fiscal authority follows the $\operatorname{plan} f_{t}^{*}\left(\mathbf{s}^{t}\right)$. The optimal targeting rules can be found by substituting the restriction on $\gamma_{f}$ into equations (11) and (12), since they are optimal for any $\gamma_{f}$. We obtain

$$
\begin{gathered}
f_{t}+y_{t}=-\varphi\left(y_{t}+\epsilon_{p} \pi_{t}\right) \\
\epsilon_{p} \pi_{t}+\Delta y_{t}=\chi\left(1+\varphi \epsilon_{p} \lambda\right)\left(f_{t}+y_{t}\right)-\chi\left(f_{t-1}+y_{t-1}\right) .
\end{gathered}
$$

Let $\mathcal{C}_{0}^{D}$ be the competitive equilibrium satisfying equations (15) and (16). Therefore, by Proposition 1, the optimal monetary policy strategy is a rule of the form (8) with $\gamma_{f}=\gamma_{f}^{* *}$, and functions $r_{t}^{*}\left(\mathbf{s}^{t}\right), \pi_{t}^{*}\left(\mathbf{s}^{t}\right), f_{t}^{*}\left(\mathbf{s}^{t}\right)$ belonging to $\mathcal{C}_{0}^{D}$. The monetary rule and the optimal fiscal strategy $F^{*}\left(\mathbf{s}^{t}\right)$ implied by condition (15) define the equilibrium of the policy game. Since $\delta_{r}$ is nonzero, by Result 2 , the fiscal stance is not necessarily neutral. If $g_{t}=0$ indeed, (16) reduces to

$$
\epsilon_{p} \pi_{t}+\Delta y_{t}=0,
$$

which may differ from the discretionary monetary targeting rule (7). This is because the two policymakers solve different problems even though they are both benevolent. The central bank would like to smooth the impact of shocks over the cycle and transfer part of their burden to the future. In fact, in case a bad (good) shock hits, it is welfare improving to smooth its impact on output and inflation over time. By committing to future deflation (inflation), current inflation falls (rises), given output, through the effect on expected inflation, and part of the impact of the current shock is transferred to the future. This expectation channel improves the trade-off between inflation and output gap stabilization. However, the fiscal policymaker does not take into account the benefits of the current tightening in terms of past outcomes, since she moves sequentially. Then, fiscal policy tries to bring the policy stance in line with her own cost-benefit evaluation, by deviating from $g=0$. As a consequence, the central bank has to trade-off deviations of inflation and the output gap from the full commitment solution against deviations of public expenditure from Pareto efficiency. Hence, discretionary fiscal policy worsens the conventional trade-off between inflation and output gap stabilization faced by the monetary authority.

It is interesting to see how monetary policy optimally reacts to deviations from a neutral fiscal stance. Under restricted strategies, the central bank does not threaten to raise the nominal interest rate in response to the fiscal gap. Rather, she manipulates the trade-offs faced by the fiscal authority through the equilibrium play. In fact, the central bank internalizes the misbehavior of the fiscal policymaker and she chooses to deviate from the rule that would be implemented under commitment and perfect coordination. This is because the monetary authority is willing to accept higher volatility of inflation and/or output to give the fiscal authority the incentive to contain the volatility of expenditure. As a consequence, coherently with the reaction function of the fiscal policymaker, optimal monetary policy targets deviations from a neutral fiscal stance; larger deviations call for higher inflation or larger output gap. The optimal policy is inertial; lagged fiscal variables appear in the targeting rule. 

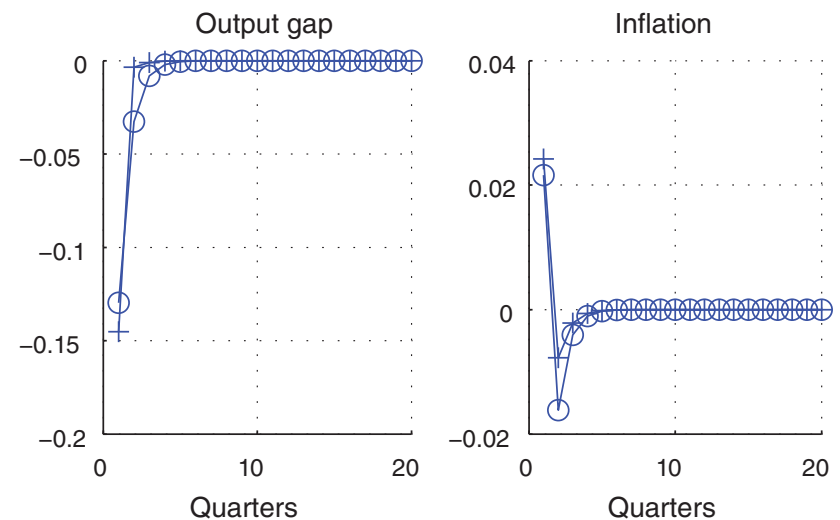

Government expenditure gap

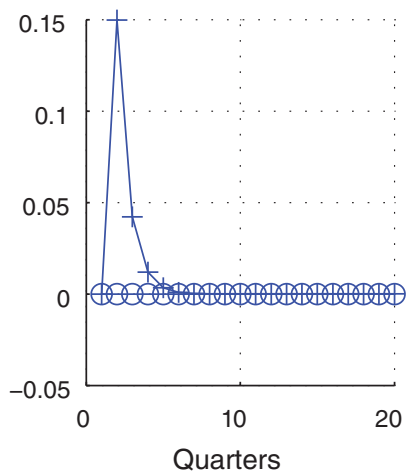

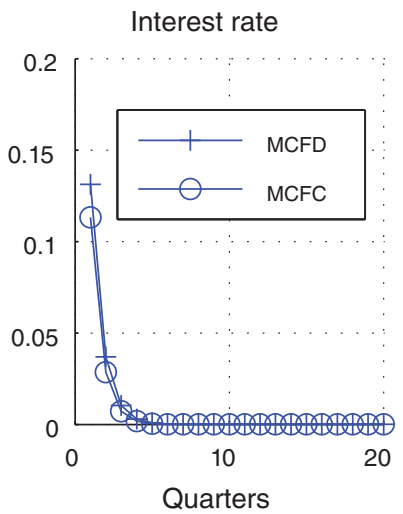
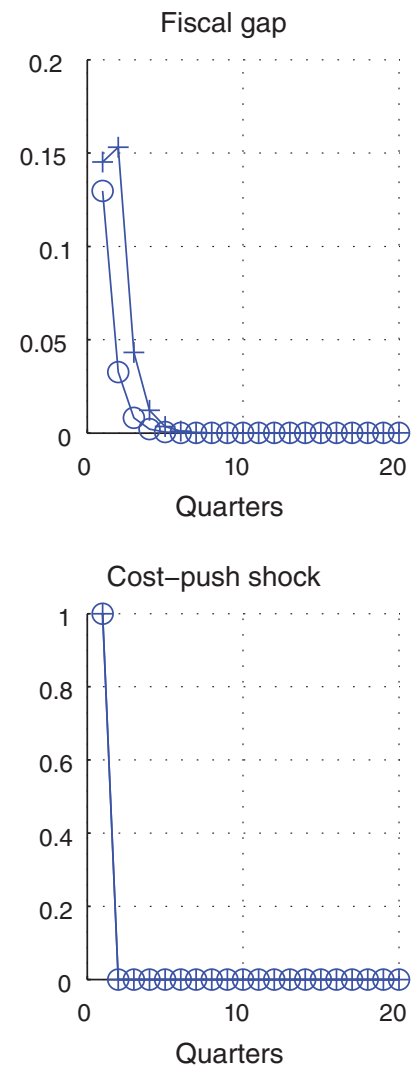

Figure 1. Impulse Responses under the Full Commitment Regime and under the Optimal Restricted Strategy, Respectively Denoted by “MCFC" and "MCFD”

Notes: The serial correlation of the shock has been set to 0 . Parameters are calibrated as in Table 1.

Then, for given future fiscal gaps, the central bank commits to tighten future monetary policy in the event of an increase of the current fiscal gap. This improves the current trade-off by reducing expected future inflation.

There is only one special case when the full commitment solution can be implemented despite fiscal discretion. In the absence of cost-push shocks, the Pareto efficient allocation is feasible, so it must also be optimal. Consequently, the commitment and the discretionary monetary targeting rules coincide on the equilibrium path and the right-hand side of equation (15) is compatible with the left-hand side of equation (16) if $g_{t}=0$. Therefore, we can state the following result.

RESULT 4: In the optimal policy mix under restricted strategies, the fiscal stance is neutral if and only if the Pareto efficient allocation is feasible.

Impulse response functions to a wage mark-up shock confirm the intuition grasped by looking at the targeting rules. Figures 1 and 2 display the response of endogenous variables, under the two regimes: commitment on the part of both authorities, 

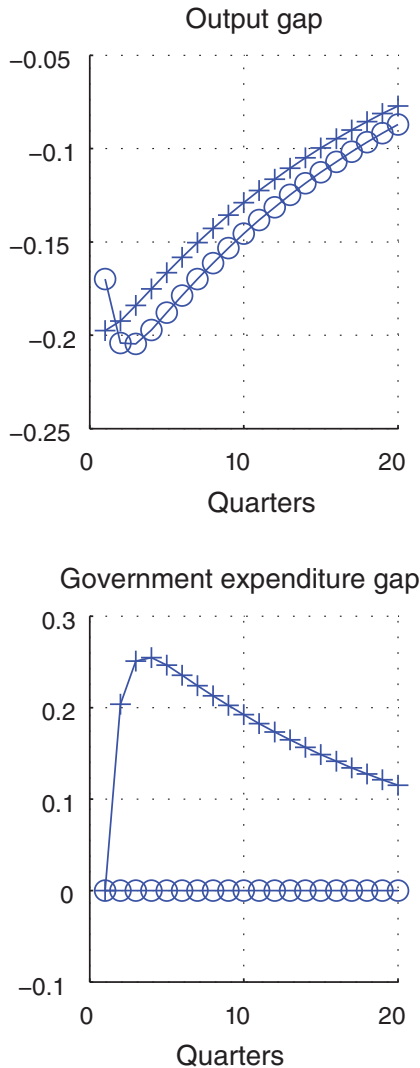
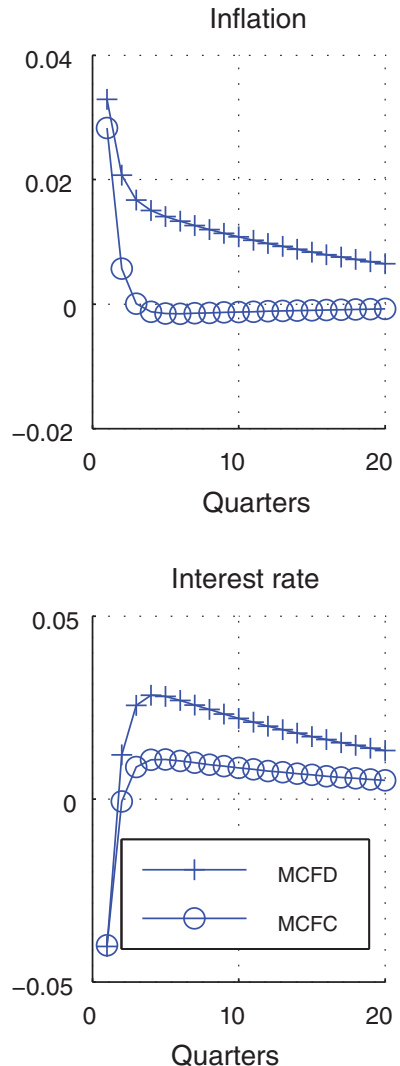

Fiscal gap

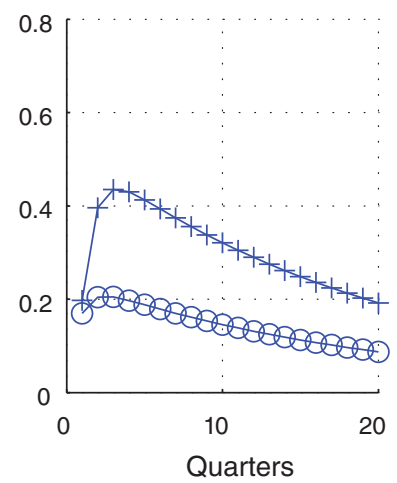

Cost-push shock

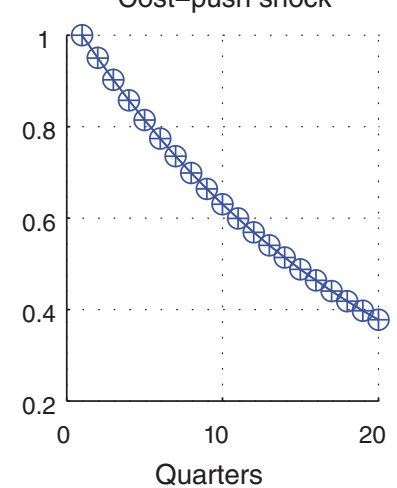

Figure 2. Impulse Responses under the Full Commitment Regime and under the Optimal Restricted Strategy, Respectively Denoted by "MCFC" and "MCFD"

Notes: The serial correlation of the shock has been set to 0.95 . Parameters are calibrated as in Table 1.

labelled as "MCFC," and discretionary fiscal policy with monetary commitment, labelled as "MCFD." Structural parameters are the same as in Galí and Monacelli (2008) and they are reported in Table 1. $\varphi$ is set equal to three, implying a labor supply elasticity of one-third. The elasticity of substitution among goods and labor types $\epsilon_{p}$ and $\epsilon_{w}$ are equal to 6, which is consistent with average mark-ups of 20 percent. $\theta$ and $\beta$ are, respectively, set to 0.75 and 0.99 . The steady-state share of government spending in output, $\chi$, is parameterized to 0.25 , the average of final government consumption for the Euro Area.

Wage mark-up shocks are assumed to follow an autoregressive process:

$$
\mu_{t+1}^{w}=\rho_{u} \mu_{t}^{w}+\varepsilon_{t+1, u} .
$$

The standard deviation of $\varepsilon_{t, u}$ is chosen in such a way that the standard deviation of the cost-push term appearing in the Phillips curve, $\lambda \mu_{t}^{w}$, is equal to 1 percent. Figures 1 and 2 report the case of a wage mark-up shock with correlations equal to 0 and 0.95 , respectively. The shock makes it impossible to simultaneously stabilize 
TABLE 1 -PARAMETERIZATION

\begin{tabular}{lc}
\hline \hline Parameter & Value \\
\hline$\varphi$ & 3 \\
$\epsilon_{p}=\epsilon_{w}$ & 6 \\
$\theta$ & 0.75 \\
$\beta$ & 0.99 \\
$\chi$ & 0.25 \\
\hline
\end{tabular}

inflation and the output gap. Hence, because of the concavity of the welfare function, it is optimal to temporarily accept both some positive inflation and a negative output gap. In addition, in the case of commitment and perfect coordination, the fiscal stance remains neutral. In fact, the government expenditure gap is closed and the fiscal gap fluctuates one-to-one with the output gap. Instead, under fiscal discretion the government expenditure gap responds to wage mark-up shocks. This fact worsens the trade-off between inflation and output gap stabilization faced by the central bank. A committed central bank could still eliminate fiscal overreaction completely by behaving as a discretionary monetary authority. Though feasible, this policy would be sub-optimal, therefore a combination of positive inflation, output gap and fiscal gap variability is preferred. In fact, the monetary authority gives up the active use of the expectation channel to some extent so as to contain fiscal misbehavior. Equilibrium fluctuations represent the maximum deviation from full commitment that the monetary authority is willing to accept so as to reduce public spending variability. Finally, although the fiscal rule targets contemporaneous variables, monetary policy induces inertia by suitably choosing her policy instrument. This is evident from Figure 1. Since the cost-push shock is serially uncorrelated, inertia must be entirely generated by monetary policy. This is a well-established result since Woodford (2003) and Galí (2008).

\section{Restricted versus Unrestricted Strategies}

We now discuss the economic relevance of the equilibria computed above, which are the outcomes of alternative reactions on the part of the central bank to fiscal misbehavior.

In the case of restricted strategies, we follow the classic Ramsey (1927) approach, where the optimal plan prescribes a nominal interest rate path that is not contingent on the fiscal authority's actions. We find that the central bank chooses to deviate from the full commitment solution in order to manipulate the fiscal authority's stabilization trade-off and contain the inefficiently high volatility of government expenditure.

In the case of unrestricted strategies, we follow the sophisticated policy approach emphasized by Chari and Kehoe (1990) and Atkeson, Chari, and Kehoe (2010) which differs from the optimal Ramsey plan in a crucial way. A sophisticated monetary rule indeed prescribes an interest rate path for any possible history, including those that are off equilibrium. Equivalently, the central bank threatens to punish deviations of the fiscal gap from the full commitment plan by varying the nominal 
interest rate. Since there exists a sufficiently tough punishment that makes any fiscal deviation unprofitable, the full commitment solution is sustained and the threat is never executed at equilibrium.

Clearly, unrestricted strategies dominate restricted ones in terms of welfare, given that the associated equilibrium outcome is constrained efficient. However, one can show that if the central bank observes the fiscal gap with some noise, the restricted strategy is the optimal limiting behavior when the noise grows large.

We model imperfect information by assuming some measurement error according to

$$
f_{t}^{o}=f_{t}+\varepsilon_{t M}
$$

where $f^{o}$ and $f$ are respectively the observed and the actual fiscal gap, while $\varepsilon_{t M}$ is a zero mean measurement error that is serially uncorrelated, with standard deviation denoted by $\sigma_{e}$. We need to redefine the game accordingly. Hence, let the sequence of events be $\mathbf{q}_{t}=\left(\mathbf{s}_{t}, f_{t}, \varepsilon_{t M}, r_{t},\left(\pi_{t}, y_{t}\right)\right)$ and the information sets be $\mathbf{h}_{t F}=\left(\mathbf{h}_{t-1}, \mathbf{s}_{t}\right)$, $\mathbf{h}_{t M}=\left(\mathbf{h}_{t-1}, \mathbf{s}_{t}, f_{t}^{o}\right)$ and $\mathbf{h}_{t Y}=\left(\mathbf{h}_{t-1}, \mathbf{s}_{t}, f_{t}, \varepsilon_{t M}, r_{t}\right)$. Obviously, the error does not enter the history of the central bank, ${ }^{19}$ while we still assume that the private sector has perfect information. We can then restate ${ }^{20}$ Proposition 1.

PROPOSITION 2: Implementation under Imperfect Information. Let $\left(\hat{\boldsymbol{\sigma}}_{\pi}, \hat{\boldsymbol{\sigma}}_{y}\right)$ be such that for any $\boldsymbol{\sigma}_{r}$ and $\boldsymbol{\sigma}_{f}, \mathcal{A}\left(\mathbf{h}_{t Y} ; \boldsymbol{\sigma}\right)$ is a continuation competitive equilibrium. Let $f_{t}^{*}\left(\mathbf{s}^{t}\right), r_{t}^{*}\left(\mathbf{s}^{t}\right), \pi_{t}^{*}\left(\mathbf{s}^{t}\right)$, and $y_{t}^{*}\left(\mathbf{s}^{t}\right)$ form a competitive equilibrium. For any $\gamma_{f}$ and any $\gamma_{\pi}>1$, define monetary and fiscal strategies $\hat{\boldsymbol{\sigma}}_{r}$ and $\hat{\boldsymbol{\sigma}}_{f}$ :

$$
\begin{gathered}
r_{t}\left(\mathbf{h}_{t M}\right)=r_{t}^{*}\left(\mathbf{s}^{t}\right)+\gamma_{f}\left(f_{t}^{o}\left(\mathbf{h}_{t F}\right)-f_{t}^{*}\left(\mathbf{s}^{t}\right)\right)+\gamma_{\pi}\left(E_{t}\left(\pi_{t}\left(\mathbf{h}_{t Y}\right) \mid \mathbf{h}_{t M}\right)-\pi_{t}^{*}\left(\mathbf{s}^{t}\right)\right) \\
f_{t}\left(\mathbf{h}_{t F}\right)=F_{t}\left(\mathbf{s}^{t}\right) .
\end{gathered}
$$

Then, if $F_{t}=f_{t}^{*}$ for any $\mathbf{s}^{t}$, the unique bounded outcome of the game is

$$
\begin{gathered}
r_{t}=r_{t}^{*}+r_{f} \varepsilon_{t M} \\
y_{t}=y_{t}^{*}-r_{f} \varepsilon_{t M} \\
\pi_{t}=\pi_{t}^{*}-\lambda(1+\varphi) r_{f} \varepsilon_{t M} .
\end{gathered}
$$

Recall that the coefficient $r_{f}$ has been previously defined by equation (10). Notice that the monetary rule differs from the one under perfect information in two respects. First, the interest rate responds to the observed fiscal gap. Moreover, we replace inflation by its expectation conditional on $\mathbf{h}_{t M}$ to emphasize that the inflation rate inferred from (2) and (3), conditionally on the observed fiscal gap, may differ from

\footnotetext{
${ }^{19}$ We are implicitly assuming that the central bank cannot perfectly see other aggregate variables that would allow her to infer $f_{t}$ with certainty.

${ }^{20}$ See Appendix B for the proof.
} 
actual inflation. According to Proposition 2, if the measurement error converges to zero, the outcome of the game converges to any desired competitive equilibrium, as in the case of unrestricted strategies under perfect information. Hence, by substituting outcomes, we can conveniently rewrite the objective function as the sum of two independent components

$$
W_{t}\left(\mathbf{s}^{t}, \varepsilon_{t M} ; \boldsymbol{\sigma}\right)=W_{t}^{P}\left(\mathbf{s}^{t} ; \boldsymbol{\sigma}\right)-\frac{1}{2} \frac{\sigma_{e}^{2} r_{f}^{2}(1+\varphi)}{1-\beta}\left[\epsilon_{p} \lambda(1+\varphi)+1\right],
$$

where $W_{t}^{P}\left(\mathbf{s}^{t} ; \boldsymbol{\sigma}\right)$ is the value of the objective function at the outcome of the game under perfect information. Since $r_{f}$ and $\varepsilon_{f}$ are given for the fiscal policymaker, it immediately follows that if $\sigma_{f}$ is optimal conditionally on $r_{f}$ under perfect information, it must also be optimal under imperfect information. We can apply the same decomposition (24) at time $t=0$ to reformulate the optimal monetary policy problem. Therefore, one can first find the best policy under perfect information, conditionally on any $\gamma_{f}$, by solving for the competitive equilibrium satisfying (11) and (12). This operation determines optimal parameters $r_{t}^{*}\left(\mathbf{s}^{t} ; \gamma_{f}\right), \pi_{t}^{*}\left(\mathbf{s}^{t} ; \gamma_{f}\right)$ and $f_{t}^{*}\left(\mathbf{s}^{t} ; \gamma_{f}\right)$. Finally, one can solve for the optimal monetary strategy by maximizing $W_{0}$ over $\gamma_{f}$, where $W_{0}^{P}$ is evaluated at the perfect information outcome. It is evident that under imperfect information the central bank faces an additional trade-off. In fact, as long as $\sigma_{e}>0$, welfare losses due to the measurement error can be reduced by weakening the response of the nominal interest rate to the fiscal gap. Equation (24) implies that such losses are zero in the case of restricted strategies. On the other hand, we showed above that only unrestricted strategies allow to implement the constrained efficient allocation. In this respect, lowering $r_{f}$ is welfare detrimental. Figure 3 displays the optimal response $r_{f}$ as a function of the standard deviation of the measurement error, in the case of the parametrization displayed in Table 1. When the error is sufficiently volatile, the restricted strategy is the optimal one.

To conclude, if the central bank can perfectly observe the fiscal gap, she can implement full commitment by threatening to vary the nominal interest rate enough to discourage deviations from a neutral fiscal stance. Since the threat is credible, it does not need to be executed at equilibrium. However, under imperfect information, in order to be credible, the monetary authority needs to punish every deviation, even if it is due to measurement error. Hence, discouraging fiscal misbehavior by varying the nominal interest rate becomes costly. The optimal monetary policy is then to accept some extra volatility of inflation and the output gap. We view the case of imperfect observability of the fiscal gap as a plausible one. Reliable data on government expenditure are released indeed with non trivial lags, moreover public spending and output need to be observed in deviation from their efficient levels. Therefore, we conclude that the model with imperfect information rationalizes the case of restricted strategies, which give the correct limiting behavior.

\section{E. Second Moments and Welfare Implications}

We conclude our analysis by studying second moments and welfare, conditionally on wage mark-up shocks, under two alternative policy regimes: full commitment, 


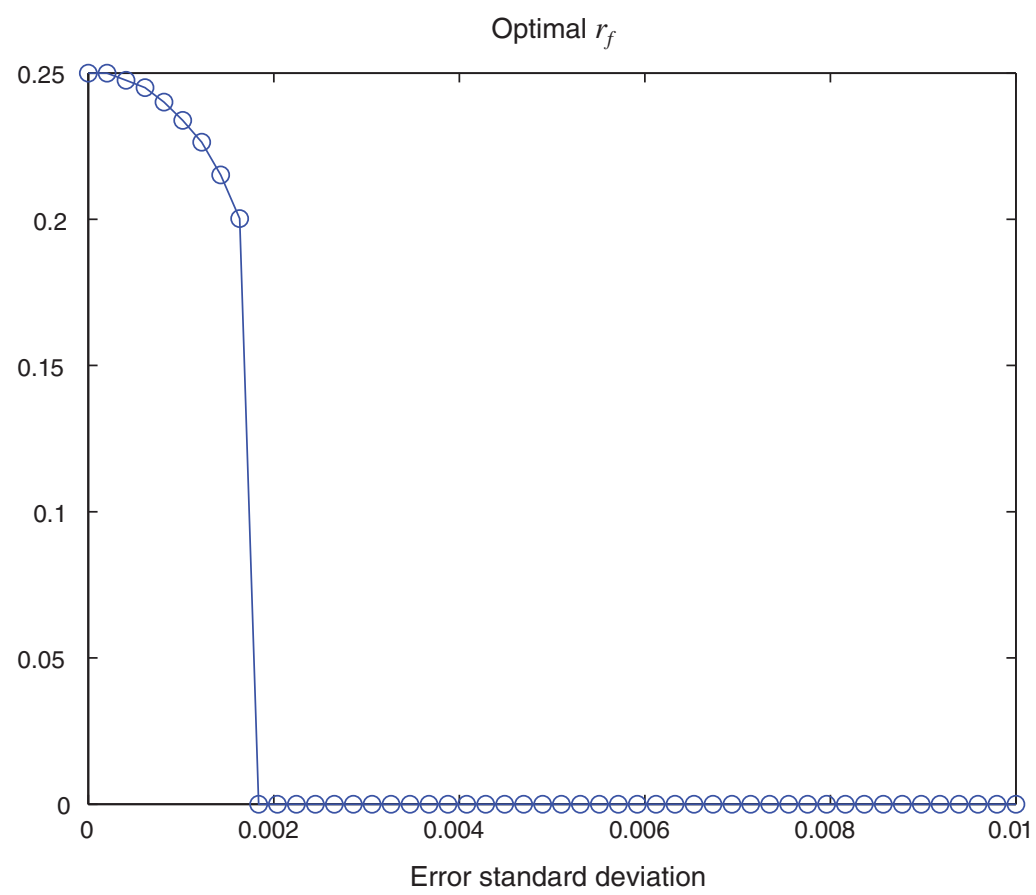

Figure 3. The Graph Displays the Optimal $r_{f}$ as a Function of the Standard Deviation OF THE MEASUREMENT ERROR

Note: Parameters are chosen as in Table 1.

or equivalently, the equilibrium under unrestricted strategies; and the equilibrium under restricted strategies. The purpose of the exercise is to show that if the central bank does not condition the nominal interest rate on the fiscal gap, lack of commitment on the fiscal side significantly reduces gains from monetary commitment.

Table 2 reports the standard deviations of the output gap, inflation and the fiscal gap under both regimes. Keeping in mind that the variance of the shock has been normalized, second moments show that the solution to the trade-offs depends on $\rho_{u}$. If the shock is purely transitory, it is worth using the expectation channel to smooth the shock. Furthermore, fiscal overreaction is less persistent and, therefore, less harmful. As a result, monetary policy gives up on fiscal gap stabilization and focuses on inflation. In contrast, when the shock is persistent, smoothing the shock is less of an issue and fiscal overexpansion is strong and long lasting. It follows that the central bank gives up on inflation and contains $g$ by over-stabilizing output, as compared to the full commitment solution, and pleasing the fiscal policymaker.

Table 3 analyzes gains from monetary commitment. The two columns consider the cases of a wage mark-up shock with serial correlations equal to 0.95 and 0 , respectively. The first three rows report welfare under full commitment, fiscal discretion with monetary commitment and full discretion. The fourth one displays the change in welfare resulting from implementing a full commitment regime starting from discretion on the part of all policymakers. Row 5 shows the change in welfare 
Table 2-Percentage Standard Deviations

\begin{tabular}{|c|c|c|c|c|c|c|}
\hline & \multicolumn{2}{|c|}{ Output gap } & \multicolumn{2}{|c|}{ Fiscal gap } & \multicolumn{2}{|c|}{ Inflation } \\
\hline & $\rho=0$ & $\rho=0.95$ & $\rho=0$ & $\rho=0.95$ & $\rho=0$ & $\rho=0.95$ \\
\hline Fiscal discretion, $r_{f}=0$ & 1.69 & 2.37 & 2.51 & 5.55 & 0.29 & 0.23 \\
\hline Full commitment & 1.56 & 2.60 & 1.56 & 2.60 & 0.31 & 0.10 \\
\hline
\end{tabular}

TABle 3-Welfare Analysis

\begin{tabular}{lcc}
\hline \hline & $\rho=0.95$ & $\rho=0$ \\
\hline Full commitment & 0.15 & 0.08 \\
Fiscal discretion and monetary commitment, $r_{f}=0$ & 0.18 & 0.09 \\
Full discretion & 0.21 & 0.10 \\
(1) Gains from monetary commitment, fiscal commitment & 0.06 & 0.02 \\
(2) Gains from monetary commitment, fiscal discretion & 0.03 & 0.01 \\
Ratio of (2) to (1) & 0.5 & 0.5 \\
\hline
\end{tabular}

Note: Welfare losses are measured in consumption equivalents under all regimes, i.e., the percentage of efficient steady state consumption that households would be willing to give up in order to switch from the actual regime to the efficient allocation.

resulting from implementing monetary commitment under fiscal discretion starting from discretion on the part of all policymakers. Finally, the last row computes the fraction of gains from monetary commitment under fiscal discretion, as compared to the full commitment case. It is possible to see that gains are only half of the ones obtained when the fiscal authority is also committing.

\section{Conclusion}

This paper considers a noncooperative game between monetary and fiscal policy, where the fiscal policymaker cannot commit to future policies. We find that should the monetary authority fail to provide the fiscal policymaker with the appropriate incentives, fluctuations of public spending undermine the stabilization goals of the central bank.

Two possible applications of our findings are worth exploring.

On the one hand, it is not obvious that government expenditure is the proper instrument to deal with asymmetric shocks in currency areas as a substitute to the nominal exchange rate. It may also be the case that the use of discretionary public spending for stabilization purposes is welfare reducing, as compared to a situation where the role of governments is limited to the efficient provision of public goods.

On the other hand, a richer fiscal policy problem may allow us to gain additional insights. At present, the analysis is confined to the case of a balanced budget and lump sum taxation. However, distortionary taxation and debt are likely to make the problems arising from sequential policymaking harsher. Adam and Billi (2010) represent a step forward in this direction. Interestingly, noncooperation and lack of fiscal commitment may provide a rationale for budget rules as long as the 
volatility of public spending translates into volatility of debt through tax smoothing. These rules are widely implemented in the United States, the United Kingdom, and the European Union. The effectiveness and the optimality of budget rules have been the subject of an extensive discussion in the fiscal policy literature. Alesina and Tabellini (1990), Andres and Domenech (2006), Diaz-Gimenez et al. (2008), Canova and Pappa (2006), Galí and Perotti (2003), and Fatas and Mihov (2006) are just a sample. However, none of those contributions focuses on the problems that lack of coordination between monetary and fiscal authorities may create, and none of the authors relate them to fiscal institutions. This is a question left for future research.

\section{Appendix A: The Model}

\section{A. Firms}

There is a perfectly competitive firm producing a single homogeneous good according to the following CES production function

$$
Y_{t}=\left[\int_{0}^{1} Y_{t}(j)^{\frac{\epsilon_{p}-1}{\epsilon_{p}}} d j\right]^{\frac{\epsilon_{p}}{\epsilon_{p}-1}},
$$

where $\epsilon_{p}>1$ is the elasticity of substitution between intermediate goods $Y_{t}(j)$. Let $P_{t}(j)$ be the price of good $j \in[0,1]$, then cost minimization implies that the price of the final good $Y$ equals the marginal cost so that

$$
P_{t}=\left[\int_{0}^{1} P_{t}(j)^{1-\epsilon_{p}} d j\right]^{\frac{1}{1-\epsilon_{p}}} .
$$

Each good $j$ is produced by a monopolistically competitive firm with a constant return to scale technology

$$
Y_{t}(j)=A_{t} N_{t, j}
$$

and productivity denoted by $A_{t}$. Prices are staggered à la Calvo and in every period firms face a constant probability $1-\theta$ of changing the price. The effective labor input is a CES aggregator of the quantity hired of differentiated labor services $N_{t, j}(i)$

$$
N_{t, j}=\left[\int_{0}^{1} N_{t, j}(i)^{\frac{\epsilon_{w, t}-1}{\epsilon_{w, t}}} d i\right]^{\frac{\epsilon_{w, t}}{\epsilon_{w, t}-1}} .
$$

Wages are set monopolistically by households, and they are taken as given by firms who do not have market power on the labor market. $\epsilon_{w, t}>1$ is representing the 
elasticity of substitution among labor types and we assume it to be time varying and stochastic so as to generate exogenous fluctuations of the wage mark-up. The aggregate wage is defined as

$$
W_{t}=\left[\int_{0}^{1} W_{t}(i)^{1-\epsilon_{w, t}} d i\right]^{\frac{1}{1-\epsilon_{w, t}}}
$$

and it has the property that the minimum cost of a unit of composite labor input $N_{t}$ is $W_{t}$.

\section{B. Households}

Each household $i$ consumes private and public goods and sells differentiated labor services to firms. Preferences are described by the following utility function

$$
U_{0}^{i}=E_{0} \sum_{t=0}^{\infty} \beta^{t}\left((1-\chi) \log C_{t}^{i}+\chi \log G_{t}-\frac{\left(N_{t}^{i}\right)^{1+\varphi}}{1+\varphi}\right)
$$

$C_{t}^{i}$ is bought at the market price $P_{t}, G_{t}$ is the public expenditure chosen by the fiscal policymaker and $N_{t}^{i}$ represents hours worked. The period budget constraint reads as

$$
P_{t} C_{t}^{i}+E_{t}\left\{Q_{t, t+1} D_{t+1}^{i}\right\} \leq D_{t}^{i}+\left(1+\tau^{w}\right) W_{t}^{i} N_{t}^{i}+T_{t}^{i}
$$

$W_{t}^{i} N_{t}^{i}$ is nominal labor income, $\tau_{w}$ is a proportional subsidy to labor income and $T_{t}^{i}$ are lump-sum taxes. In addition, households hold a portfolio including state contingent assets and shares in domestic firms. $D_{t+1}^{i}$ denotes the nominal payoff of the portfolio in $t+1, Q_{t, t+1}$ is the one-period ahead stochastic discount factor and it is such that $E_{t}\left\{Q_{t, t+1}\right\} R_{t}=1$, where $R_{t}$ is the risk-free nominal interest rate factor. Optimization requires

$$
\begin{gathered}
\frac{W_{t}}{P_{t}}=\frac{\varepsilon_{w, t}}{\left(\varepsilon_{w, t}-1\right)\left(1+\tau^{w}\right)} \frac{N_{t}^{\varphi} C_{t}}{1-\chi} \\
1=\beta E_{t}\left\{\frac{C_{t}}{C_{t+1}} R_{t} \frac{P_{t}}{P_{t+1}}\right\},
\end{gathered}
$$

where index $i$ has been dropped because we are interested in a symmetric equilibrium. We define the wage mark-up as

$$
\mu_{t}^{w}=\log \left(\frac{\varepsilon_{w, t}}{\left(\varepsilon_{w, t}-1\right)\left(1+\tau^{w}\right)}\right)
$$


so that equation (A8) becomes

$$
\frac{W_{t}}{P_{t}}=\exp \left\{\mu_{t}^{w}\right\} \frac{N_{t}^{\varphi} C_{t}}{1-\chi}
$$

\section{Market Clearing}

The clearing of all goods markets implies

$$
Y_{t}=C_{t}+G_{t}
$$

The aggregate production function is given by

$$
Y_{t} Z_{t}=A_{t} N_{t}
$$

where $Z_{t}$ is defined as

$$
Z_{t}=\int_{0}^{1} \frac{Y_{t}(j)}{Y_{t}} d j
$$

and represents a measure of relative price dispersion. It can be proved that $\log (Z)$ is a function of the cross-sectional variance of relative prices and it is of second order. $N_{t}$ is the aggregate labor input

$$
N_{t}=\int_{0}^{1} N_{t, j} d j
$$

\section{The Pareto Optimum}

Pareto efficiency requires the marginal rate of substitution between leisure and private consumption and between leisure and public consumption to equalize the corresponding marginal rate of transformation, this implying

$$
A_{t}=N_{t}^{\varphi} \frac{C_{t}}{1-\chi}=N_{t}^{\varphi} \frac{G_{t}}{\chi} .
$$

The goods market clearing condition and the aggregate production function are used to recover the efficient allocation

$$
\bar{N}_{t}=1 ; \quad \bar{Y}_{t}=A_{t} ; \quad \bar{C}_{t}=(1-\chi) A_{t} ; \quad \bar{G}_{t}=\chi A_{t} .
$$




\section{E. Derivation of Equation (2)}

Profit maximization in the intermediate goods sector determines the optimal price $P_{t}^{*}$ charged by reoptimizing firms

$$
\sum_{T=0}^{\infty} \theta^{T} E_{t}\left\{Q_{t, t+T} Y_{t+T}(j)\left[P_{t}^{*}-\frac{\epsilon_{p}}{\epsilon_{p}-1}\left(1-\tau^{p}\right) \frac{W_{t+T}}{A_{t+T}}\right]\right\}=0,
$$

where $\tau^{p}$ is a subsidy to production. Log-linearizing (A18) and (A2) about the nonstochastic steady-state allows to recover a standard Phillips curve

$$
\pi_{t}=\beta E_{t}\left\{\pi_{t+1}\right\}+\lambda\left(\hat{w}_{t}-a_{t}\right),
$$

where $\hat{w}_{t}$ represents the real wage in log-deviation from the steady-state, $\pi_{t}=\log P_{t}-\log P_{t-1}, a_{t}=\log A_{t}$ and $\lambda$ is a convolution of deep parameters

$$
\lambda=\frac{(1-\theta)(1-\theta \beta)}{\theta} .
$$

Labor supply (A11) in its log-linear form reads as

$$
\hat{w}_{t}=\varphi \hat{n}_{t}+\hat{c}_{t}+\mu_{t}^{w},
$$

while log-linearizing the resource constraint $(\mathrm{RC})$ and the production function (APF) yields

$$
\hat{y}_{t}=(1-\chi) \hat{c}_{t}+\chi \hat{g}_{t}=a_{t}+\hat{n}_{t},
$$

so that the real marginal cost, $\hat{w}_{t}-a_{t}$, can be rewritten as a function of output, government expenditure, TFP, and wage mark-up shocks after using (A21) in (A20)

$$
\hat{w}_{t}-a_{t}=\left(\varphi+\frac{1}{1-\chi}\right) \hat{y}_{t}-(1+\varphi) a_{t}-\frac{\chi}{1-\chi} \hat{g}_{t}+\mu_{t}^{w} .
$$

Hence, it follows that

$$
\bar{w}_{t}-a_{t}=\left(\varphi+\frac{1}{1-\chi}\right) \bar{y}_{t}-(1+\varphi) a_{t}-\frac{\chi}{1-\chi} \bar{g}_{t}+\mu_{t}^{w},
$$

where lower case variables with a bar denote the value of the variable computed at the Pareto efficient allocation in log deviations from the steady-state. Log deviations of the real marginal cost have to be zero at Pareto efficiency. Then, it must be the case that

$$
\hat{w}_{t}-a_{t}=\left(\varphi+\frac{1}{1-\chi}\right) y_{t}-\frac{\chi}{1-\chi} g_{t},
$$


which is easily obtained by subtracting the right hand side of (A23) from the righthand side of (A22) and using definitions stated in (1). For convenience, we want to express the Phillips curve as a function of the fiscal gap, hence (A24) becomes

$$
\hat{w}_{t}-a_{t}=(1+\varphi) y_{t}-\frac{\chi}{1-\chi} f_{t}+\mu_{t}^{w}
$$

by using the definition of $f_{t}$. (A25) and (A19) imply the Phillips curve (2) reported in the text.

\section{F. Derivation of Equation (3)}

Log linearizing the Euler equation one can obtain

$$
c_{t}=E_{t} c_{t+1}-\left\{r_{t}-E_{t} \pi_{t+1}-r r_{t}\right\}
$$

after defining $c_{t}=\hat{c}_{t}-\bar{c}_{t} r_{t}=\log R_{t}, \rho=-\log \beta$ and $r r_{t}=\rho+E_{t} \Delta a_{t+1}$. It follows from the resource constraint (A21) and the definition of $f_{t}$ that

$$
c_{t}=(1-\chi)^{-1} y_{t}-\chi(1-\chi)^{-1} g_{t}=y_{t}-\chi(1-\chi)^{-1} f_{t} .
$$

Equations (A27) and (A26) imply the IS (3) stated in the text.

Appendix B: Proofs and Derivations of Results Stated in Section IV

\section{A. Proposition 1}

Let $\left\{\tilde{f}_{t}^{*}\left(\mathbf{s}^{t}\right), \pi_{t}^{*}\left(\mathbf{s}^{t}\right), \tilde{y}_{t}^{*}\left(\mathbf{s}^{t}\right), r_{t}^{*}\left(\mathbf{s}^{t}\right)\right\}$ be a competitive equilibrium. Define monetary and fiscal strategies $\left\{\sigma_{r}, \sigma_{f}\right\}$ as

$$
\begin{gathered}
r_{t}=r_{t}^{*}\left(\mathbf{s}^{t}\right)+\gamma_{f}\left(f_{t}-f_{t}^{*}\left(\mathbf{s}^{t}\right)\right)+\gamma_{\pi}\left(\pi_{t}-\pi_{t}^{*}\left(\mathbf{s}^{t}\right)\right) \\
f_{t}=f_{t}^{*}\left(\mathbf{s}^{t}\right)
\end{gathered}
$$

for any $\gamma_{f}$ and any $\gamma_{\pi}>1$. Then, the unique solution to equations (2), (3), (B1), and (B2) is $\left\{f_{t}^{*}\left(\mathbf{s}^{t}\right), \pi_{t}^{*}\left(\mathbf{s}^{t}\right), y_{t}^{*}\left(\mathbf{s}^{t}\right), r_{t}^{*}\left(\mathbf{s}^{t}\right)\right\}$.

PROOF:

By definition of the competitive equilibrium, $\left\{f_{t}^{*}, \pi_{t}^{*}, y_{t}^{*}, r_{t}^{*}\right\}$ satisfies equations (2) and (3). Then, it must be true that for any collection $\left\{f_{t}, \pi_{t}, y_{t}, r_{t}\right\}$ satisfying (2), (3), (B1), and (B2), the following system holds

$$
\pi_{t}-\pi_{t}^{*}=\beta E_{t}\left(\pi_{t+1}-\pi_{t+1}^{*}\right)+\lambda(1+\varphi)\left(y_{t}-y_{t}^{*}\right)
$$




$$
y_{t}-y_{t}^{*}=E_{t}\left(y_{t+1}-y_{t+1}^{*}\right)-\left[\gamma_{\pi}\left(\pi_{t}-\pi_{t}^{*}\right)-E_{t}\left(\pi_{t+1}-\pi_{t+1}^{*}\right)\right] .
$$

Equivalently,

$$
\left[\begin{array}{c}
y_{t}-y_{t}^{*} \\
\pi_{t}-\pi_{t}^{*}
\end{array}\right]=\Omega \mathbf{A} E_{t}\left[\begin{array}{c}
y_{t+1}-y_{t+1}^{*} \\
\pi_{t+1}-\pi_{t+1}^{*}
\end{array}\right],
$$

where

$$
\begin{gathered}
\Omega=\left(1+\gamma_{\pi} \lambda(1+\varphi)\right)^{-1} \\
\mathbf{A}=\left[\begin{array}{cc}
1 & 1-\gamma_{\pi} \beta \\
\lambda(1+\varphi) & \beta+\lambda(1+\varphi)
\end{array}\right] .
\end{gathered}
$$

The system has a unique solution if and only if the eigenvalues of matrix $\mathbf{A}$ are both inside the unit circle. As Bullard and Mitra (2002) show, this is the case if and only if $\gamma_{\pi}>1$. Hence, $\gamma_{\pi}>1$ guarantees that $y_{t}=y_{t}^{*}$ and $\pi_{t}=\pi_{t}^{*}$ is the unique solution for any $\mathbf{s}^{t}$. It also follows by (B1) that $r_{t}=r_{t}^{*}$, while $f_{t}=f_{t}^{*}$ because of (B2).

\section{B. The Fiscal Policy Problem}

Fiscal policy maximizes $W_{t}$ in each period $t$, subject to (2), (3), and (8), given expectations about future variables and exogenous stochastic processes. First-order conditions with respect to inflation, output gap and fiscal gap are respectively given by

$$
\begin{gathered}
\frac{\epsilon_{p}}{\lambda} \pi_{t}+\psi_{\pi, t}+\gamma_{\pi} \psi_{r, t}=0 \\
(1+\varphi) y_{t}-\lambda(1+\varphi) \psi_{\pi, t}+\psi_{r, t}=0 \\
\frac{\chi}{1-\chi} f_{t}+\lambda \frac{\chi}{1-\chi} \psi_{\pi, t}+\left(\gamma_{f}-\frac{\chi}{1-\chi}\right) \psi_{r, t}=0,
\end{gathered}
$$

together with the constraints (2) and (3), where $\psi_{\pi, t}$ and $\psi_{r, t}$ are the Lagrange multipliers associated to (2) and (3), respectively. Equation (B10) can be equivalently rewritten as

$$
f_{t}+\delta_{\pi} \pi_{t}+\delta_{y} y_{t}=0
$$

being $\delta_{\pi}$ and $\delta_{y}$ defined as

$$
\delta_{y}=(1+\varphi)\left[1-\frac{(1-\chi)}{\chi} r_{f}\right] ; \quad \delta_{\pi}=\epsilon_{p}\left(\delta_{y}-1\right) .
$$


After some algebraic manipulation, equation (B11) can be expressed as in (11). The rule (B11) implicitly defines the optimal fiscal strategy that can be found after using (8) into (2), (3), and (11) and solving

$$
\mathbf{B}\left[\begin{array}{l}
y_{t} \\
\pi_{t} \\
f_{t}
\end{array}\right]=\mathbf{D} E_{t}\left[\begin{array}{c}
y_{t+1} \\
\pi_{t+1} \\
f_{t+1}
\end{array}\right]+\left[\begin{array}{c}
-\left(r_{t}^{*}\left(\mathbf{s}^{t}\right)-\gamma_{\pi} \pi_{t}^{*}\left(\mathbf{s}^{t}\right)-\gamma_{f} f_{t}^{*}\left(\mathbf{s}^{t}\right)-r r_{t}\right) \\
\lambda \mu_{t}^{w} \\
0
\end{array}\right],
$$

where matrices $\mathbf{B}$ and $\mathbf{D}$ are

$$
\mathbf{B}=\left[\begin{array}{ccc}
1 & \gamma_{\pi} & -\frac{\chi}{1-\chi}+\gamma_{f} \\
-\lambda(1+\varphi) & 1 & \lambda \frac{\chi}{1-\chi} \\
\delta_{y} & \delta_{\pi} & 1
\end{array}\right]
$$

$$
\mathbf{D}=\left|\begin{array}{ccc}
1 & 1 & -\frac{\chi}{1-\chi} \\
0 & \beta & 0 \\
0 & 0 & 0
\end{array}\right|
$$

If a unique locally stable solution to the system exists, ${ }^{21}$ then the optimal fiscal strategy $F^{*}\left(\mathbf{s}^{t}\right) \equiv f_{t}\left(r_{t}^{*}\left(\mathbf{s}^{t}\right), \pi_{t}^{*}\left(\mathbf{s}^{t}\right), f_{t}^{*}\left(\mathbf{s}^{t}\right), \mathbf{s}^{t} ; \boldsymbol{\sigma}\right)$ is a linear function that only depends on the history of the exogenous events. The following proposition guarantees that if the fiscal policymaker plays her optimal strategy, the central bank can always choose a monetary policy rule that implements any competitive equilibrium satisfying (11). Obviously, any competitive equilibrium that does not satisfy (11) cannot satisfy $F^{*}$ and thus cannot be an equilibrium of the policy game either.

PROPOSITION A: Let $\mathfrak{C}_{0}$ be a bounded competitive equilibrium satisfying (11) and be $\left(\hat{\boldsymbol{\sigma}}_{\pi}, \hat{\boldsymbol{\sigma}}_{y}\right)$, such that for any $\boldsymbol{\sigma}_{r}$ and $\boldsymbol{\sigma}_{f}, \mathcal{A}\left(\mathbf{h}_{t} ; \boldsymbol{\sigma}\right)$ is a continuation competitive equilibrium. If (a) fiscal policy is optimal, i.e., $f_{t}\left(\mathbf{s}^{t} ; \boldsymbol{\sigma}\right)=F^{*}\left(\mathbf{s}^{t}\right),(b) F^{*}$ is unique, (c) the monetary policy strategy is of the form $(8)$, with $r_{t}^{*}\left(\mathbf{s}^{t}\right), \pi_{t}^{*}\left(\mathbf{s}^{t}\right)$, and $f_{t}^{*}\left(\mathbf{s}^{t}\right)$ belonging to $\mathrm{C}_{0}$, then there exists a unique bounded outcome $\mathcal{A}_{0}$ coinciding with $\mathrm{C}_{0}$ and $F^{*}=f_{t}^{*}\left(\mathbf{s}^{t}\right)$. 


\section{PROOF:}

By assumption (c), $r_{t}^{*}\left(\mathbf{s}^{t}\right), \pi_{t}^{*}\left(\mathbf{s}^{t}\right)$, and $f_{t}^{*}\left(\mathbf{s}^{t}\right)$ satisfy equations (2), (3), and (11). Any outcome of the game $\left\{f_{t}, \pi_{t}, y_{t}, r_{t}\right\}$ satisfies (2), (3), (8), as well as (11) by assumption (a) and by the definition of $F^{*}$. Hence, the following system must hold

$$
\mathbf{B}\left[\begin{array}{c}
y_{t}-y_{t}^{*} \\
\pi_{t}-\pi_{t}^{*} \\
f_{t}-f_{t}^{*}
\end{array}\right]=\mathbf{D} E_{t}\left[\begin{array}{c}
y_{t+1}-y_{t+1}^{*} \\
\pi_{t+1}-\pi_{t+1}^{*} \\
f_{t+1}-f_{t+1}^{*}
\end{array}\right],
$$

where matrices $\mathbf{B}$ and $\mathbf{D}$ have been defined above. The system has as a unique solution, $y_{t}=y_{t}^{*}, \pi_{t}=\pi_{t}^{*}$ and $f_{t}=f_{t}^{*}$, if and only if the eigenvalues of the matrix $\mathbf{B}^{-1} \mathbf{D}$ are inside the unit circle, which is true whenever the optimal fiscal strategy is unique. Hence, by assumption b) there must exist a unique bounded outcome $\mathcal{A}_{0}$ coinciding with $\mathrm{C}_{0}$ and $F_{t}^{*}=f_{t}^{*}$.

This proposition guarantees that it is immaterial whether the central bank internalizes the targeting rule or the optimal fiscal strategy of the form (FPS). Hence, in the main text we only look at the fiscal targeting rule that lends itself to a straightforward interpretation.

\section{The Monetary Policy Problem}

The first-order conditions with respect to inflation, output gap, and fiscal gap are respectively given by

$$
\begin{gathered}
\frac{\epsilon_{p}}{\lambda} \pi_{t}+\Delta \xi_{\pi, t}+\delta_{\pi} \xi_{f, t}=0 \\
(1+\varphi) y_{t}-\lambda(1+\varphi) \xi_{\pi, t}+\delta_{y} \xi_{f, t}=0 \\
\frac{\chi}{1-\chi} f_{t}+\lambda \frac{\chi}{1-\chi} \xi_{\pi, t}+\xi_{f, t}=0,
\end{gathered}
$$

where $\xi_{\pi, t}, \xi_{f, t}$ are the Lagrange multipliers associated with (2) and (B11) respectively. (B18) and (B19) allow to express lagrange multipliers as functions of output and fiscal gaps

$$
\begin{gathered}
\xi_{\pi, t}=\frac{(1-\chi)(1+\varphi)}{\lambda\left[(1-\chi)(1+\varphi)+\chi \delta_{y}\right]} y_{t}-\frac{\chi \delta_{y}}{\lambda\left[(1-\chi)(1+\varphi)+\chi \delta_{y}\right]} f_{t} \\
\xi_{f, t}=-\frac{\chi(1+\varphi)}{(1-\chi)(1+\varphi)+\chi \delta_{y}}\left(y_{t}+f_{t}\right) .
\end{gathered}
$$

Substituting back into (B17) yields the monetary policy rule (12) in the text. 


\section{Proposition 2}

Implementation under Imperfect Information. Let $\left(\hat{\boldsymbol{\sigma}}_{\pi}, \hat{\boldsymbol{\sigma}}_{y}\right)$ be such that for any $\boldsymbol{\sigma}_{r}$ and $\boldsymbol{\sigma}_{f}, \mathcal{A}\left(\mathbf{h}_{t} ; \boldsymbol{\sigma}\right)$ is a continuation competitive equilibrium. Let $f_{t}^{*}\left(\mathbf{s}^{t}\right), r_{t}^{*}\left(\mathbf{s}^{t}\right), \pi_{t}^{*}$ $\left(\mathbf{s}^{t}\right)$ and $y_{t}^{*}\left(\mathbf{s}^{t}\right)$ form a competitive equilibrium. For any $\gamma_{f}$ and any $\gamma_{\pi}>1$, define monetary and fiscal strategies $\hat{\boldsymbol{\sigma}}_{r}$ and $\hat{\boldsymbol{\sigma}}_{f}$ :

$$
\begin{gathered}
r_{t}\left(\mathbf{h}_{t M}\right)=r_{t}^{*}\left(\mathbf{s}^{t}\right)+\gamma_{f}\left(f_{t}^{o}\left(\mathbf{h}_{t F}\right)-f_{t}^{*}\left(\mathbf{s}^{t}\right)\right)+\gamma_{\pi}\left(E_{t}\left(\pi_{t}\left(\mathbf{h}_{t Y}\right) \mid \mathbf{h}_{t M}\right)-\pi_{t}^{*}\left(\mathbf{s}^{t}\right)\right) \\
f_{t}\left(\mathbf{h}_{t F}\right)=F_{t}\left(\mathbf{s}^{t}\right) .
\end{gathered}
$$

Then, if $F_{t}\left(\mathbf{s}^{t}\right)=f_{t}^{*}\left(\mathbf{s}^{t}\right)$, the unique bounded outcome of the game is

$$
\begin{gathered}
r_{t}=r_{t}^{*}+r_{f} \varepsilon_{t M} \\
\tilde{y}_{t}=\tilde{y}_{t}^{*}-r_{f} \varepsilon_{t M} \\
\pi_{t}=\pi_{t}^{*}-\lambda(1+\varphi) r_{f} \varepsilon_{t M} .
\end{gathered}
$$

\section{PROOF:}

Use (B22) into (2) and (3) after replacing everywhere $f_{t}$ with $f_{t}^{o}$ and solve for $\pi_{t}-\pi_{t}^{*}, y_{t}-y_{t}^{*}$ and $r_{t}-r_{t}^{*}$. Then, the definition of $f_{t}^{o}$ immediately implies the expression for the nominal interest rate. Now use the nominal interest rate in (2) and (3), impose $f_{t}=f_{t}^{*}$ and solve for $\pi_{t}-\pi_{t}^{*}$ and $y_{t}-y_{t}^{*}$. The expressions stated in the proposition are immediately obtained.

\section{REFERENCES}

Adam, Klaus, and Roberto M. Billi. 2008. "Monetary Conservatism and Fiscal Policy." Journal of Monetary Economics 55 (8): 1376-88.

Adam, Klaus, and Roberto M. Billi. 2010. "Distortionary Fiscal Policy and Monetary Policy Goals." Federal Reserve Bank (FRB) of Kansas City Research Working Paper RWP 10-10.

Alesina, Alberto, and Guido Tabellini. 1990. "A Positive Theory of Fiscal Deficits and Government Debt." Review of Economic Studies 57 (3): 403-14.

-Andrés, Javier, and Rafael Doménech. 2006. "Automatic Stabilizers, Fiscal Rules and Macroeconomic Stability." European Economic Review 50 (6): 1487-1506.

-Atkeson, Andrew, V. V. Chari, and Patrick J. Kehoe. 2010. "Sophisticated Monetary Policies." Quarterly Journal of Economics 125 (1): 47-89.

- Barro, Robert J. 1979. "On the Determination of the Public Debt." Journal of Political Economy 87 (5): 940-71.

- Beetsma, Roel, and Henrik Jensen. 2005. "Monetary and Fiscal Policy Interactions in a Micro-Founded Model of a Monetary Union." Journal of International Economics 67 (2): 320-52.

-Benigno, Gianluca, and Pierpaolo Benigno. 2006. "Designing Targeting Rules for International Monetary Policy Cooperation.” Journal of Monetary Economics 53 (3): 473-506.

- Benigno, Pierpaolo. 2002. "A Simple Approach to International Monetary Policy Coordination." Journal of International Economics 57 (1): 177-96.

- Bullard, James, and Kaushik Mitra. 2002. "Learning about Monetary Policy Rules.” Journal of Monetary Economics 49 (6): 1105-29.

Canova, Fabio, and Evi Pappa. 2006. "The Elusive Costs and the Immaterial Gains of Fiscal Constraints." Journal of Public Economics 90 (8-9): 1391-1414.

Canzoneri, Matthew B., and Jo Anna Gray. 1985. "Monetary Policy Games and the Consequences of Non-Cooperative Behavior." International Economic Review 26 (3): 547-64. 
Canzoneri, Matthew B., and Dale W. Henderson. 1992. Monetary Policy in Interdependent Economies: A Game-Theoretic Approach. Cambridge, MA: MIT Press.

Chari, V. V., and Patrick J. Kehoe. 1990. "Sustainable Plans." Journal of Political Economy 98 (4): 783-802.

Clarida, Richard, Jordi Galí, and Mark Gertler. 1999. "The Science of Monetary Policy: A New Keynesian Perspective.” Journal of Economic Literature 37 (4): 1661-1707.

-Clarida, Richard, Jordi Galí, and Mark Gertler. 2002. "A Simple Framework for International Monetary Policy Analysis.” Journal of Monetary Economics 49 (5): 879-904.

Coenen, Gunter, Giovanni Lombardo, Frank Smets, and Roland Straub. 2010. "International Transmission and Monetary Policy Cooperation." In International Dimensions of Monetary Policy, edited by Jordi Galí and Mark J. Gertler, 157-92. Cambridge, MA: National Bureau of Economic Research.

Diaz-Giménez, Javier, Giorgia Giovannetti, Ramon Marimon, and Pedro Teles. 2008. "Nominal Debt as a Burden to Monetary Policy." Review of Economic Dynamics 11 (3): 493-514.

Dixit, Avinash, and Luisa Lambertini. 2003. "Interactions of Commitment and Discretion in Monetary and Fiscal Policies." American Economic Review 93 (5): 1522-42.

Eser, Fabian, Campbell Leith, and Simon Wren-Lewis. 2009. "When is Monetary Policy All We Need?" University of Oxford Economics Series Working Paper 430.

-Fatas, Antonio, and Ilian Mihov. 2006. "The Macroeconomic Effects of Fiscal Rules in the US States." Journal of Public Economics 90 (1-2): 101-17.

Galí, Jordi. 2003. "New Perspectives on Monetary Policy, Inflation and the Business Cycle." In Advances in Economics and Econometrics: Theory and Applications, Vol. 3, edited by Mathias Dewatripont, Lars Peter Hansen, and Stephen J. Turnovsky, 151-97. Cambridge, UK: Cambridge University Press.

Galí, Jordi. 2008. Monetary Policy, Inflation and the Business Cycle. Princeton: Princeton University Press.

Galí, Jordi, and Tommaso Monacelli. 2008. "Optimal Monetary and Fiscal Policy in a Currency Union.” Journal of International Economics 76 (1): 116-32.

Galí, Jordi, and Roberto Perotti. 2003. "Fiscal Policy and Monetary Integration in Europe." Economic Policy 18 (37): 533-72.

Klein, Paul, Per Krusell, and José-Victor Ríos-Rull. 2008. “Time-Consistent Public Policy.” Review of Economic Studies 75 (3): 789-808.

Kydland, Finn, and Edward Prescott. 1977. "Rules Rather than Discretion: The Inconsistency of Optimal Plans." Journal of Political Economy 85 (3): 473-90.

Leith, Campbell, and Leopold Von Thadden. 2008. "Monetary and Fiscal Policy Interactions in a New Keynesian Model with Capital Accumulation and Non-Ricardian Consumers." Journal of Economic Theory 140 (1): 279-313.

Liu, Zheng, and Evi Pappa. 2008. "Gains from International Monetary Policy Coordination: Does It Pay to Be Different?” Journal of Economic Dynamics and Control 32 (7): 2085-2117.

Lucas, Robert E., Jr., and Nancy L. Stokey. 1983. "Optimal Fiscal and Monetary Policy in an Economy without Capital.” Journal of Monetary Economics 12 (1): 55-93.

Ramsey, Frank P. 1927. "A Contribution to the Theory of Taxation.” Economic Journal 37 (1): 47-61.

-Rogoff, Kenneth. 1985. "The Optimal Degree of Commitment to an Intermediate Monetary Target." Quarterly Journal of Economics 100 (4): 1169-89.

Rotemberg, Julio, and Michael Woodford. 1997. "An Optimization-Based Econometric Framework for the Evaluation of Monetary Policy." In NBER Macroeconomic Annual 1997, edited by Ben S. Bernanke and Julio J. Rotemberg, 297-346. Cambridge, MA: MIT Press.

Sargent, Thomas J., and Neil Wallace. 1981. "Some Unpleasant Monetarist Arithmetic." Federal Reserve Bank of Minneapolis Quarterly Review 5 (3): 1-17.

Schmitt-Grohé, Stephanie, and Martín Uribe. 2004. "Optimal Fiscal and Monetary Policy under Sticky Prices.” Journal of Economic Theory 114 (2): 198-230.

Schmitt-Grohé, Stephanie, and Martín Uribe. 2007. "Optimal Simple and Implementable Monetary and Fiscal Rules.” Journal of Monetary Economics 54 (6): 1702-25.

Woodford, Michael. 2003. Interest and Prices. Princeton: Princeton University Press. 